\title{
A Review Study on Macrolides Isolated from Cyanobacteria
}

\author{
Mengchuan Wang ${ }^{1}$, Jinrong Zhang ${ }^{1, *}$, Shan $\mathrm{He}^{1}$ and Xiaojun Yan ${ }^{2}$ \\ 1 School of Marine Sciences, Laboratory of Marine Natural Products, Ningbo University, Ningbo 315211, \\ China; mengchuanwang1@163.com (M.W.); heshan@nbu.edu.cn (S.H.) \\ 2 Key Laboratory of Applied Marine Biotechnology of Ministry of Education, Ningbo University, \\ Ningbo 315211, China; yanxiaojun@nbu.edu.cn \\ * Correspondence: zhangjinrong@nbu.edu.cn; Tel./Fax: +86-574-8760-0458
}

Academic Editor: Anake Kijjoa

Received: 27 January 2017; Accepted: 24 April 2017; Published: 26 April 2017

\begin{abstract}
Cyanobacteria are rich sources of structurally-diverse molecules with promising pharmacological activities. Marine cyanobacteria have been proven to be true producers of some significant bioactive metabolites from marine invertebrates. Macrolides are a class of bioactive compounds isolated from marine organisms, including marine microorganisms in particular. The structural characteristics of macrolides from cyanobacteria mainly manifest in the diversity of carbon skeletons, complexes of chlorinated thiazole-containing molecules and complex spatial configuration. In the present work, we systematically reviewed the structures and pharmacological activities of macrolides from cyanobacteria. Our data would help establish an effective support system for the discovery and development of cyanobacterium-derived macrolides.
\end{abstract}

Keywords: cyanobacteria; macrolides; secondary metabolites; bioactivity

\section{Introduction}

Cyanobacteria, also known as blue-green algae, including cyanobacteria from terrestrial, freshwater and marine ecosystems, are a group of ancient photosynthetic prokaryotes. As defensive chemicals, structurally-diverse secondary metabolites from cyanobacteria have been proven to greatly contribute to successful survival and reproduction of cyanobacteria in changing, complex and diverse environments during the long-lasting evolutionary process [1]. At present, hundreds of compounds with important bioactivities have been isolated from terrestrial or marine cyanobacteria [2]. Macrolides are a class of important bioactive compounds, which are commonly found in marine organisms, including cyanobacteria [3]. Some marine macrolides are promising candidates for future applications in medicine. For example, bryostatin-1 shows potent antitumor activity in phase I cancer clinical trials [4]. Macrolide antibiotics, such as erythromycin and polyene macrolides, have been employed for widespread application of severe bacterial infections [5]. Structurally-diverse macrolides from cyanobacteria often contain unique and unusual substituents, including chlorinated residues, thiazole residues [6] or pyran residues [7]. Macrolides usually exhibit potent antitumor or antibacterial activities [8]. In addition, cyanobacteria have great potentials as sustainable sources for production of bioactive macrolides because of their rapid growth, genetic tractability and cultivable property [2]. Although cyanobacteria possess cultivable properties similar to those of microorganisms, cyanobacteria have attracted far less attention than microorganisms.

In the present review paper, we systematically summarized the structures and bioactivities of macrolides isolated from cyanobacteria, and over 50 references were cited. Up to the end of 2016, a total of 64 macrolide compounds have been isolated from cyanobacteria, including 49 macrolides from marine cyanobacteria and 15 macrolides from terrestrial cyanobacteria, most of which are mainly from 
Lyngbya, Scytonema and Oscillatoria. It has been reported that most of these cyanobacterium-derived macrolides possess several noticeable bioactivities, including antitumor, antibacterial, antimalarial and toxicity to animals. This review summarizes new macrolides derived from cyanobacteria, providing useful information in the further discovery of novel cyanobacterial macrolides.

\section{Anti-Neoplastic Property of Cyanobacterium-Derived Macrolides on Different Cell Lines}

Nitrogen mustard has been used in the treatment of lymphoma cancer since 1940s, and more than 100 anti-cancer drugs are widely used in the world. Until now, natural products have largely contributed to cancer therapy and become an indispensable source for the development of innovative anti-cancer drugs [9]. Most macrolides from cyanobacteria display significant cytotoxicity to cancer cells. Cyanobacteria of the genera Symploca, Lyngbya, Scytonema and Oscillatoria are important sources of anti-cancer macrolides. Cyanobacterium-derived macrolides reported to have anti-neoplastic effects on different cell lines are given in Figure 1 and Table 1.

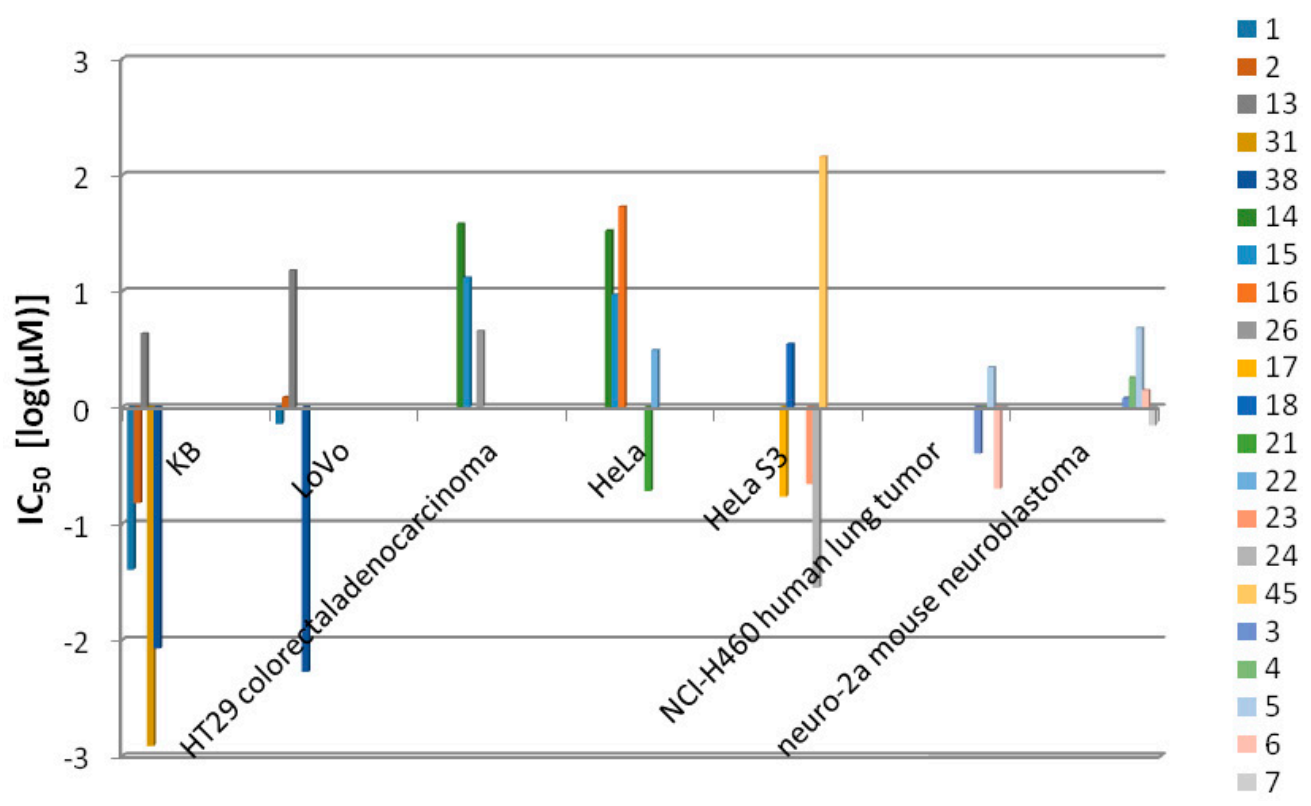

Figure 1. Anti-neoplastic profiling results for cyanobacterium-derived macrolides on different cell lines. Data are represented as $\mathrm{IC}_{50}[\log (\mu \mathrm{M})]$.

Table 1. Anti-neoplastic property of cyanobacterium-derived macrolides on different cell lines.

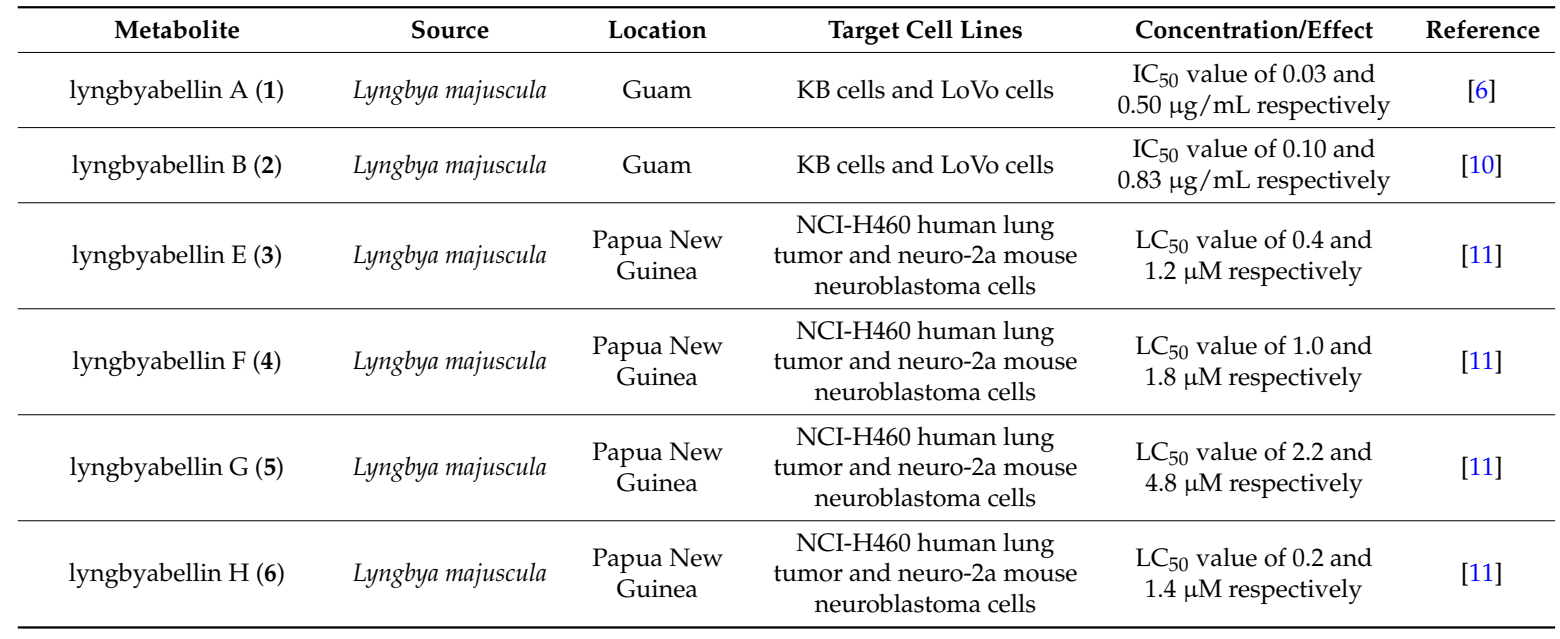


Table 1. Cont.

\begin{tabular}{|c|c|c|c|c|c|}
\hline Metabolite & Source & Location & Target Cell Lines & Concentration/Effect & Reference \\
\hline lyngbyabellin I (7) & Lyngbya majuscula & $\begin{array}{l}\text { Papua New } \\
\text { Guinea }\end{array}$ & $\begin{array}{l}\text { NCI-H460 human lung } \\
\text { tumor and neuro-2a mouse } \\
\text { neuroblastoma cells }\end{array}$ & $\begin{array}{l}\mathrm{LC}_{50} \text { value of } 1.0 \text { and } \\
0.7 \mu \mathrm{M} \text { respectively }\end{array}$ & [11] \\
\hline lyngbyabellin N (10) & Moorea bouillonii & $\begin{array}{l}\text { Palmyra } \\
\text { Atoll, USA }\end{array}$ & $\begin{array}{l}\text { H-460 human lung } \\
\text { carcinoma and HCT116 } \\
\text { colon cancer cell lines }\end{array}$ & $\begin{array}{c}\mathrm{IC}_{50} \text { value of } \\
0.0048-1.8 \mu \mathrm{M} \text { and } \\
15 \mu \mathrm{M} \text { respectively }\end{array}$ & [12] \\
\hline lyngbyaloside B (13) & Lyngbya sp. & Palau & KB cells and LoVo cells & $\begin{array}{l}\mathrm{IC}_{50} \text { value of } 4.3 \text { and } \\
15 \mu \mathrm{M} \text { respectively }\end{array}$ & [13] \\
\hline 2-epi-lyngbyalosid (14) & Lyngbya bouillonii & $\begin{array}{l}\text { Apra Harbor, } \\
\text { Guam }\end{array}$ & $\begin{array}{c}\text { HT29 colorectal } \\
\text { adenocarcinoma and } \\
\text { HeLa cells }\end{array}$ & $\begin{array}{l}\mathrm{IC}_{50} \text { value of } 38 \text { and } \\
33 \mu \mathrm{M} \text { respectively }\end{array}$ & [14] \\
\hline 18E-lyngbyaloside C (15) & Lyngbya bouillonii & $\begin{array}{l}\text { Apra Harbor, } \\
\text { Guam }\end{array}$ & $\begin{array}{c}\text { HT29 colorectal } \\
\text { adenocarcinoma and } \\
\text { HeLa cells }\end{array}$ & $\begin{array}{l}\mathrm{IC}_{50} \text { value of } 13 \text { and } \\
9.3 \mu \mathrm{M} \text { respectively }\end{array}$ & [14] \\
\hline 18Z-lyngbyaloside C (16) & Lyngbya bouillonii & $\begin{array}{l}\text { Apra Harbor, } \\
\text { Guam }\end{array}$ & $\begin{array}{c}\text { HT29 colorectal } \\
\text { adenocarcinoma and } \\
\text { HeLa cells }\end{array}$ & $\begin{array}{l}\mathrm{IC}_{50} \text { value of }>100 \mu \mathrm{M} \\
\text { and } 53 \mu \mathrm{M} \text { respectively }\end{array}$ & [14] \\
\hline biselyngbyaside (17) & Lyngbya sp. & $\begin{array}{l}\text { Tokunoshima } \\
\text { Island, Japan }\end{array}$ & $\mathrm{HeLa} \mathrm{S}_{3}$ cells & $\mathrm{IC}_{50}$ value of $0.1 \mu \mathrm{g} / \mathrm{mL}$ & [15] \\
\hline biselyngbyaside B (18) & Lyngbya sp. & $\begin{array}{l}\text { Tokunoshima } \\
\text { Island, Japan }\end{array}$ & $\mathrm{HeLa} \mathrm{S}_{3}$ cells and HL60 cells & $\begin{array}{l}\mathrm{IC}_{50} \text { value of } 3.5 \text { and } \\
0.82 \mu \mathrm{M} \text { respectively }\end{array}$ & [16] \\
\hline biselyngbyaside E (21) & Lyngbya sp. & $\begin{array}{c}\text { Ishigaki } \\
\text { Island, Japan }\end{array}$ & HeLa and HL60 cells & $\begin{array}{l}\mathrm{IC}_{50} \text { value of } 0.19 \text { and } \\
0.071 \mu \mathrm{M} \text { respectively }\end{array}$ & [17] \\
\hline biselyngbyaside F (22) & Lyngbya sp. & $\begin{array}{c}\text { Ishigaki } \\
\text { Island, Japan }\end{array}$ & HeLa and HL60 cells & $\begin{array}{l}\mathrm{IC}_{50} \text { value of } 3.1 \text { and } \\
0.66 \mu \mathrm{M} \text { respectively }\end{array}$ & [17] \\
\hline biselyngbyolide A (23) & Lyngbya sp. & $\begin{array}{l}\text { Tokunoshima } \\
\text { Island, Japan }\end{array}$ & $\mathrm{HeLa} \mathrm{S}_{3}$ cells and HL60 cells & $\begin{array}{l}\mathrm{IC}_{50} \text { value of } 0.22 \text { and } \\
0.027 \mu \mathrm{M} \text { respectively }\end{array}$ & [18] \\
\hline biselyngbyolide B (24) & Lyngbya sp. & $\begin{array}{c}\text { Ishigaki } \\
\text { Island, Japan }\end{array}$ & $\mathrm{HeLa} \mathrm{S}_{3}$ cells and HL60 cells & $\begin{array}{l}\mathrm{IC}_{50} \text { value of } 0.028 \text { and } \\
0.0027 \mu \mathrm{M} \text { respectively }\end{array}$ & [19] \\
\hline caylobolide A (25) & Lyngbya majuscula & Bahamian & $\begin{array}{l}\text { human colon tumor cells } \\
\text { HCT } 116\end{array}$ & $\mathrm{IC}_{50}$ values of $9.9 \mu \mathrm{M}$ & [20] \\
\hline caylobolide B (26) & Phormidium spp. & Florida USA & $\begin{array}{c}\text { HT29 colorectal } \\
\text { adenocarcinoma and HeLa } \\
\text { cervical carcinoma cells }\end{array}$ & $\begin{array}{l}\mathrm{IC}_{50} \text { value of } 4.5 \text { and } \\
12.2 \mu \mathrm{M} \text { respectively }\end{array}$ & [21] \\
\hline swinholide A (27) & Symploca cf. sp. & Fiji & several cancer cell lines & $\begin{array}{c}\mathrm{IC}_{50} \text { values of } \\
0.37 \mathrm{nM}-1.0 \mu \mathrm{M}\end{array}$ & [22] \\
\hline ankaraholide A (28) & Geitlerinema sp. & Madagascar & $\begin{array}{l}\text { NCI-H460, Neuro-2a cells } \\
\text { and MDA-MB-435 cells }\end{array}$ & $\begin{array}{l}\mathrm{IC}_{50} \text { value of } 119,262 \\
\text { and } 8.9 \mathrm{nM} \text { respectively }\end{array}$ & [22] \\
\hline scytophycin A (30) & $\begin{array}{c}\text { Scytonema } \\
\text { pseudohofmanni }\end{array}$ & Oahu, Hawaii & $\begin{array}{c}\text { human carcinoma of } \\
\text { nasopharynx Cell (KB cells) }\end{array}$ & $\mathrm{IC}_{50}$ value of $1 \mathrm{ng} / \mathrm{mL}$ & [23] \\
\hline scytophycin B (31) & $\begin{array}{c}\text { Scytonema } \\
\text { pseudohofmanni }\end{array}$ & Oahu, Hawaii & KB cells & $\mathrm{IC}_{50}$ value of $1 \mathrm{ng} / \mathrm{mL}$ & [23] \\
\hline scytophycins C-E (32-34) & $\begin{array}{c}\text { Scytonema } \\
\text { pseudohofmanni }\end{array}$ & Oahu, Hawaii & KB cells & $\begin{array}{l}\mathrm{IC}_{50} \text { value of } \\
10-100 \mathrm{ng} / \mathrm{mL}\end{array}$ & [23] \\
\hline $\begin{array}{c}\text { 6-hydroxyscytophycin } \\
\text { B (35) }\end{array}$ & $\begin{array}{l}\text { Scytonema } \\
\text { mirabile }\end{array}$ & cultured & KB cells and LoVo cells & $\begin{array}{l}\text { MICs of } 1-5 \text { and } \\
10-50 \mathrm{ng} / \mathrm{mL} \\
\text { respectively }\end{array}$ & [23] \\
\hline $\begin{array}{c}19-O- \\
\text { demethylscytophycin } \\
C(36)\end{array}$ & $\begin{array}{l}\text { Scytonema } \\
\text { burmanicurn }\end{array}$ & cultured & KB cells and LoVo cells & $\begin{array}{l}\text { MICs of } 1-5 \text { and } \\
10-50 \mathrm{ng} / \mathrm{mL} \\
\text { respectively }\end{array}$ & [23] \\
\hline $\begin{array}{l}\text { 6-hydroxy-7-O- } \\
\text { methylscytophycin E (37) }\end{array}$ & $\begin{array}{l}\text { Scytonema } \\
\text { ocellatum }\end{array}$ & cultured & KB cells and LoVo cells & $\begin{array}{l}\text { MICs of } 1-5 \text { and } \\
10-50 \mathrm{ng} / \mathrm{mL} \\
\text { respectively }\end{array}$ & [23] \\
\hline tolytoxin (38) & $\begin{array}{c}\text { Tolypothrix } \\
\text { conglutinata var. } \\
\text { colorata }\end{array}$ & $\begin{array}{l}\text { Fanning } \\
\text { Island }\end{array}$ & KB cells and LoVo cells & $\begin{array}{l}\mathrm{IC}_{50} \text { value of } 8.4 \text { and } \\
5.3 \mathrm{nM} \text { respectively }\end{array}$ & [24] \\
\hline debromoaplysiatoxin (39) & Lyngbya majuscula & $\begin{array}{l}\text { Marshall } \\
\text { Islands }\end{array}$ & $\begin{array}{l}\text { P-388 lymphocytic mouse } \\
\text { leukemia }\end{array}$ & weak & [25] \\
\hline lyngbouilloside (44) & Lyngbya bouillonii & $\begin{array}{l}\text { Papua New } \\
\text { Guinea }\end{array}$ & neuroblastoma cells & $\mathrm{IC}_{50}$ value of $17 \mu \mathrm{M}$ & [26] \\
\hline
\end{tabular}


Table 1. Cont.

\begin{tabular}{|c|c|c|c|c|c|}
\hline Metabolite & Source & Location & Target Cell Lines & Concentration/Effect & Reference \\
\hline koshikalide (45) & Lyngbya sp. & $\begin{array}{c}\text { Mie } \\
\text { Prefecture }\end{array}$ & $\mathrm{HeLa}_{3}$ cells & $\mathrm{IC}_{50}$ value of $42 \mu \mathrm{g} / \mathrm{mL}$ & [27] \\
\hline sanctolide A (46) & Oscillatoria sancta & cultured & $\begin{array}{l}\text { HT-29 and MDA-MB-435 } \\
\text { cell lines }\end{array}$ & $\mathrm{nd}^{\mathrm{a}}$ & [28] \\
\hline acutiphycin (47) & $\begin{array}{l}\text { Oscillatoria } \\
\text { acutissima }\end{array}$ & $\begin{array}{l}\text { Manoa Valley } \\
\text { Oahu, Hawaii }\end{array}$ & KB cells and NIH/3T3 cells & $\mathrm{ED}_{50}<1 \mu \mathrm{g} / \mathrm{mL}$ & [29] \\
\hline $\begin{array}{l}\text { 20,21-didehydroacutiphycin } \\
\text { (48) }\end{array}$ & $\begin{array}{l}\text { Oscillatoria } \\
\text { acutissima }\end{array}$ & $\begin{array}{l}\text { Manoa Valley } \\
\text { Oahu, Hawaii }\end{array}$ & $\mathrm{KB}$ cells and $\mathrm{NIH} / 3 \mathrm{~T} 3$ cells & $\mathrm{ED}_{50}<1 \mu \mathrm{g} / \mathrm{mL}$ & [29] \\
\hline polycavernoside D (49) & Okeania sp. & Puerto Rican & $\begin{array}{l}\text { H-460 human lung cancer } \\
\text { cell lines }\end{array}$ & $\mathrm{EC}_{50}$ value of $2.5 \mu \mathrm{M}$ & [30] \\
\hline bastimolide A (50) & Okeania hirsuta & Panama & Vero cells & $\mathrm{IC}_{50}$ value of $2.1 \mu \mathrm{M}$ & [31] \\
\hline nuiapolide (51) & $\begin{array}{c}\text { colonial } \\
\text { cyanobacterium } \\
(071905-N I I-01)\end{array}$ & Hawaii & $\begin{array}{c}\text { Jurkat cells and cancerous T } \\
\text { lymphocytes }\end{array}$ & anti-chemotactic activity & [32] \\
\hline
\end{tabular}

A series of cytotoxic marine cyanobacterial metabolites, named lyngbyabellins (1-11) possessing thiazole residues and chlorine substituents, have been isolated from the cyanobacterial genus Lyngbya (Figure 2). Isolated from the marine cyanobacterium Lyngbya majuscula collected from Guam, lyngbyabellin A (1) exhibits potent in vitro cytotoxicity against human carcinoma of nasopharynx Cell (KB cells) and LoVo cells with $\mathrm{IC}_{50}$ values of 0.03 and $0.50 \mu \mathrm{g} / \mathrm{mL}$, respectively [6]. The analog of lyngbyabellin A (1), lyngbyabellin B (2), was isolated from the same strain of Lyngbya majuscula. Compared with lyngbyabellin A (1), lyngbyabellin B (2) is slightly less cytotoxic to KB and LoVo cells with $\mathrm{IC}_{50}$ values of 0.10 and $0.83 \mu \mathrm{g} / \mathrm{mL}$, respectively [10]. Five analogs of lyngbyabellin A (1), including lyngbyabellins E-I (3-7), are produced from the same strain of Lyngbya majuscula harvested in Papua New Guinea. To the best of our knowledge, lyngbyabellins E-I (3-7) have potent in vitro cytotoxicity against human lung tumor (NCI-H460) and mouse neuroblastoma (neuro-2a) cells. Lyngbyabellin E (3) and lyngbyabellin $\mathrm{H}$ (6) display significant cytotoxicity to NCI-H460 ( $\mathrm{LC}_{50}$ values of 0.4 and $0.2 \mu \mathrm{M}$, respectively) and neuro-2a cells ( $\mathrm{LC}_{50}$ values of 1.2 and $1.4 \mu \mathrm{M}$, respectively). Lyngbyabellins F-G (4-5) and lyngbyabellin I (7) are slightly less cytotoxic to NCI-H460 ( $\mathrm{LC}_{50}$ values of 1.0, 2.2 and $1.0 \mu \mathrm{M}$, respectively) and neuro-2a cells ( $\mathrm{LC}_{50}$ values of $1.8,4.8$ and $0.7 \mu \mathrm{M}$, respectively) [11]. The marine cyanobacterium Moorea bouillonii (formerly Lyngbya bouillonii) collected from Palmyra Atoll affords four analogs of lyngbyabellin A (1), lyngbyabellins K (8), L (9), N (10) and 7-epi-lyngbyabellin L (11). Lyngbyabellin N (10) shows variable cytotoxicity to H-460 human lung carcinoma $\left(\mathrm{IC}_{50}=0.0048-1.8 \mu \mathrm{M}\right)$ and potent in vitro cytotoxicity against the HCT116 colon cancer cell line $\left(\mathrm{IC}_{50}=40.9 \pm 3.3 \mathrm{nM}\right)$. This result could perhaps be explained by the solubility problem of lyngbyabellin $\mathrm{N}$ (10). The nitrogen-containing side chain (leucine statine residue) of lyngbyabellin $\mathrm{N}$ (11) may be the basic structural feature for its cytotoxic activity [12].

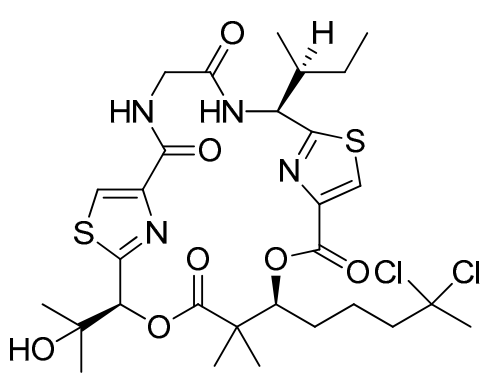

lyngbyabellin $A(1)$

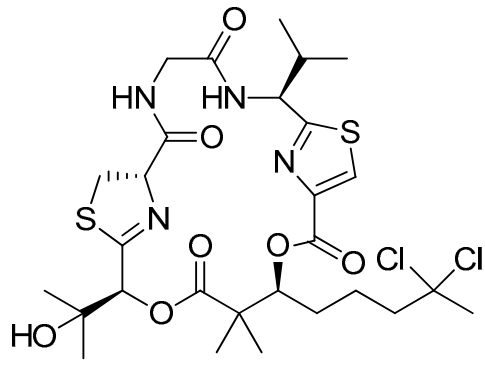

lyngbyabellin B(2)<smiles>C[C@H](O)[C@H](OC(=O)[C@@H](C)[C@@H](C)O)c1nc(C(=O)OC[C@H](O)c2nc(C(=O)O[C@H](CCCC(C)(Cl)Cl)C(C)(C)O)cs2)cs1</smiles>

lyngbyabellin G(5)

Figure 2. Cont. 
<smiles>[R]C(C)(C)[C@H](OC(=O)[C@H](C)[C@@H](CCCC(C)(Cl)Cl)OC(=O)c1csc([C@H](COC(=O)c2csc(C(CC(C)=O)OC(C)=O)n2)OC(=O)C[C@@H](NC(=O)CCC)[C@@H](CC(C)C)NC(C)=O)n1)C(C)(C)C</smiles>

lyngbyabellin $\mathrm{E}(3) \mathrm{R}=\mathrm{OH}$

lyngbyabellin $\mathrm{H}(\mathbf{6}) \mathrm{R}=\mathrm{H}$<smiles>[R]C(C)(Cl)CCC[C@H](OC(=O)c1csc(C(O)COC(=O)c2csc(C(OC(=O)[C@@H](C)C(C)C)[C@@H](C)C(=O)O)n2)n1)C(C)C</smiles>

lyngbyabellin $\mathrm{K}(8) \quad \mathrm{R}=\mathrm{Cl}$

lyngbyabellin L(9) $\quad \mathrm{R}=\mathrm{H} 7 \mathrm{~S}$

7-epi-lyngbyabellin L(11) $\mathrm{R}=\mathrm{H} 7 R$<smiles>[R]C(C)(C)C(OC(=O)[C@H](C)[C@H](CCCC(C)(Cl)Cl)OC(=O)c1csc(CNC(O)COC(=O)C[C@H](OC(C)=O)[C@@H](CC(C)C)NC(=O)CCC)n1)c1nc(C(=O)OC)cs1</smiles>

lyngbyabellin $\mathrm{F}(4) \mathrm{R}=\mathrm{OH}$

lyngbyabellin I(7) $\mathrm{R}=\mathrm{H}$

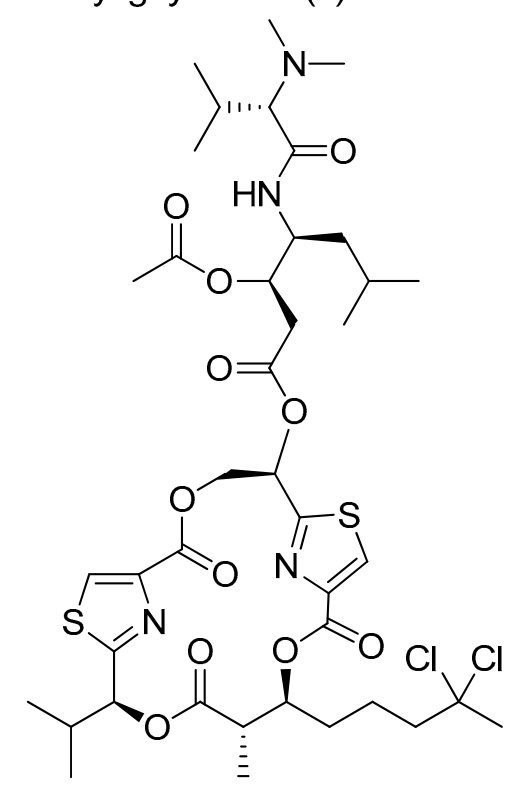

lyngbyabellin $\mathrm{N}(\mathbf{1 0})$

Figure 2. Chemical structures of Compounds 1-11.

Several 16-membered glycoside macrolides, termed lyngbyalosides, are produced from various species of the cyanobacterial genus Lyngbya (Figure 3). The marine Lyngbya bouillonii, collected from Laing Island, afford lyngbyaloside (12) [8]. Lyngbyaloside B (13), isolated from marine cyanobacterium Lyngbya sp., which was collected from Palaua, shows weak cytotoxicity against KB cells and LoVo cells with $\mathrm{IC}_{50}$ values of 4.3 and $15 \mu \mathrm{M}$, respectively [13]. The total synthesis of lyngbyaloside B (13) has been reported by Fuwa et al. [33]. Three analogs of lyngbyaloside (12), including 2-epi-lyngbyaloside (14), 18E-lyngbyaloside C (15) and 18Z-lyngbyaloside C (16), were isolated from the marine cyanobacterium Lyngbya bouillonii, collected from Apra Harbor, Guam. Cytotoxicity assays revealed that these macrolides possess weak to moderate cytotoxicity against the human colorectal 
adenocarcinoma cell line HT29 and HeLa cervical carcinoma cells. 18E-lyngbyaloside C (15) is more cytotoxic toward HT29 colorectal adenocarcinoma and HeLa cervical carcinoma cells ( $\mathrm{IC}_{50}$ values of 13 and $9.3 \mu \mathrm{M}$, respectively) than 2-epi-lyngbyaloside (14) ( $\mathrm{IC}_{50}$ values of 38 and $33 \mu \mathrm{M}$, respectively). $18 E$-Lyngbyaloside C (15) is approximately five-fold more cytotoxic than $18 Z$-lyngbyaloside C (16) ( IC $_{50}$ values of $>100 \mu \mathrm{M}$ and $53 \mu \mathrm{M}$, respectively) [14]. The total synthesis of lyngbyaloside $\mathrm{C}$ has also been accomplished [34].

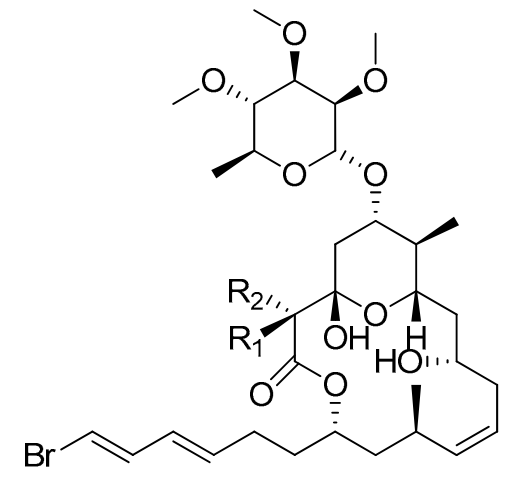

lyngbyaloside (12) $\quad \mathrm{R}_{1}=\mathrm{Me} \mathrm{R}_{2}=\mathrm{H}$

2-epi-lyngbyaloside (14) $\mathrm{R}_{1}=\mathrm{H} \quad \mathrm{R}_{2}=\mathrm{Me}$

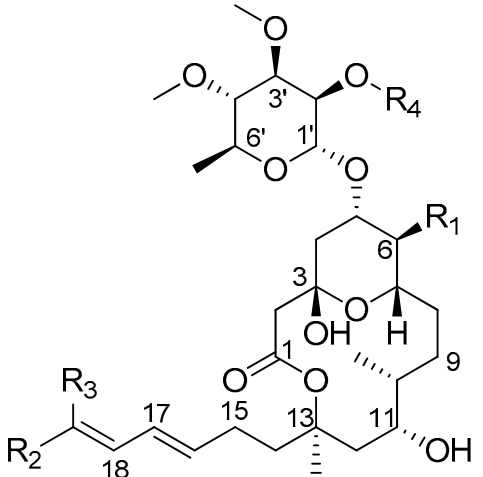

\begin{tabular}{lllll}
\hline Name & $\mathrm{R}_{1}$ & $\mathrm{R}_{2}$ & $\mathrm{R}_{3}$ & $\mathrm{R}_{4}$ \\
\hline lyngbyaloside B (13) & $\mathrm{Me}$ & $\mathrm{Br}$ & $\mathrm{H}$ & $\mathrm{H}$ \\
& & & & \\
18E-lyngbyalosides C (15) & $\mathrm{H}$ & $\mathrm{Br}$ & $\mathrm{H}$ & $\mathrm{Me}$ \\
& & & & \\
18Z-lyngbyalosides C (16) & $\mathrm{H}$ & $\mathrm{H}$ & $\mathrm{Br}$ & $\mathrm{Me}$ \\
\hline
\end{tabular}

Figure 3. Chemical structures of Compounds 12-16.

Another distinct class of 18-membered ring glycoside macrolides has been isolated from the cyanobacterial genus Lyngbya (Figure 4). Biselyngbyaside (17) was discovered through a bioassay-guided screening for cytotoxic compounds from cyanobacterium Lyngbya sp. collected from Okinawa Prefecture, Japan. Biselyngbyaside (17) shows a broad spectrum of cytotoxicity against human solid tumor cell lines, especially for $\mathrm{HeLa}_{3}$ cells with an $\mathrm{IC}_{50}$ value of $0.1 \mu \mathrm{g} / \mathrm{mL}$ [15], and its total synthesis was completed [35]. Extensive efforts toward finding cytotoxic natural products have resulted in the isolation of three analogs of biselyngbyaside (17), named biselyngbyasides B-D (18-20), from the marine cyanobacterium Lyngbya sp. Biselyngbyaside B (18) displays significant cytotoxicity against HeLa $\mathrm{S}_{3}$ and HL60 cells ( $\mathrm{IC}_{50}$ values of 3.5 and $0.82 \mu \mathrm{M}$, respectively, using thapsigargin as a positive control drug). In addition, biselyngbyasides B-D (18-20) induced apoptosis of cancer cells by inhibiting calcium influx into the endoplasmic reticulum and increasing the concentration of intracellular calcium [16]. Two analogs of biselyngbyaside (17), biselyngbyasides E (21) and F (22), were isolated from the marine cyanobacterium Lyngbya sp. collected from Ishigaki Island, Japan. In vitro cell cytotoxicity assays showed that biselyngbyaside E (21) has higher cytotoxicity against HeLa and HL60 cells ( $\mathrm{IC}_{50}$ values of 0.19 and $0.071 \mu \mathrm{M}$, respectively) than biselyngbyaside $\mathrm{F}$ (22) ( $\mathrm{IC}_{50}$ values of 3.1 and $0.66 \mu \mathrm{M}$, respectively). Based on the trisubstituted olefin geometry, the presence and absence of the sugar moiety are crucial for the biological activities [17].

Like a cytotoxic biselyngbyaside-related macrolide, biselyngbyolide A (23) was isolated from the marine cyanobacterium Lyngbya sp. harvested from Tokunoshima Island, Japan. Biselyngbyolide A (23) shows strong cytotoxicity against $\mathrm{HeLa} \mathrm{S}_{3}$ cells and HL60 cells with $\mathrm{IC}_{50}$ values of 0.22 and $0.027 \mu \mathrm{M}$, respectively [18]. Biselyngbyolide B (24) was also isolated from the same strain of Lyngbya sp. and displays significant inhibitory effects on growth of HeLa $\mathrm{S}_{3}$ cells and HL60 cells $\left(\mathrm{IC}_{50}\right.$ values of 0.028 
and $0.0027 \mu \mathrm{M}$, respectively, using thapsigargin as a positive control drug). Moreover, biselyngbyolide B (24) has 3-100-fold more potent apoptosis-inducing activity than biselyngbyaside (17) $[16,19]$.<smiles>[R2]C(/C=C/C[C@@H](OC)/C(C)=C/[C@H](C)C/C=C/C=C/CC(/C=C(/C)C/C=C/C)OC(=O)CC)C/C=C\C</smiles>

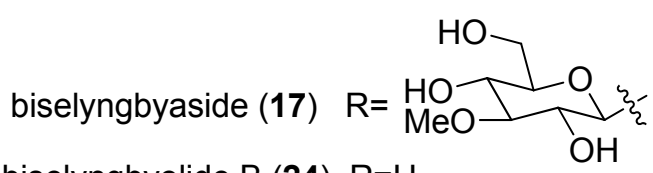
biselyngbyolide $B(24) \mathrm{R}=\mathrm{H}$

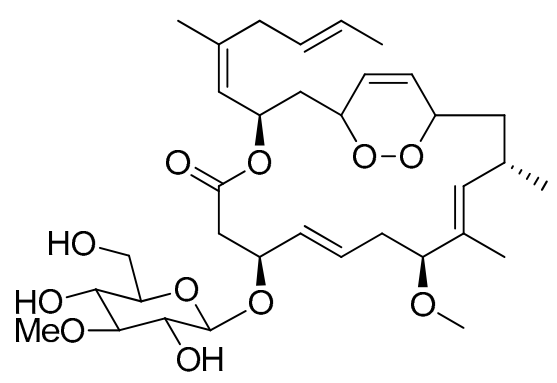

biselyngbyaside $\mathrm{C}(19)$

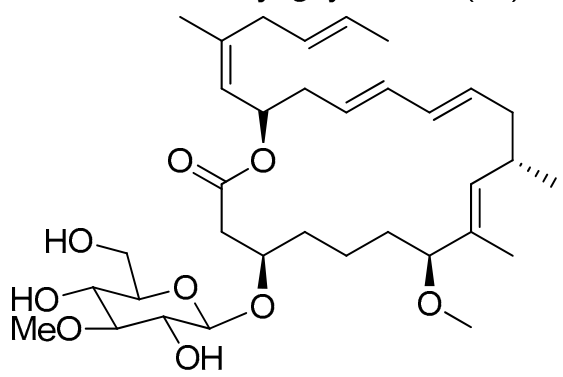

biselyngbyaside $\mathrm{E}(\mathbf{2 1})$

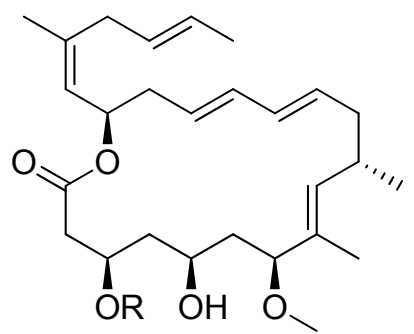

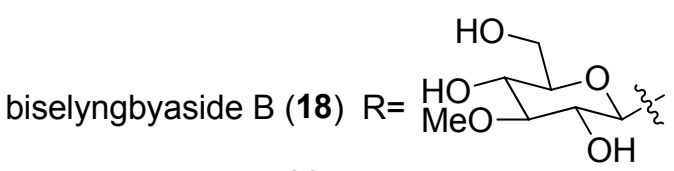
biselyngbyolide $\mathrm{A}(\mathbf{2 3}) \mathrm{R}=\mathrm{H}$<smiles>C=C(C(O)CO)C(O)C(C)C/C=C/C=C/CC(/C=C(/C)CC=CC)OC(=O)C[C@@H](/C=C/CC(OC)C(O)CO)OC(O)CO</smiles>

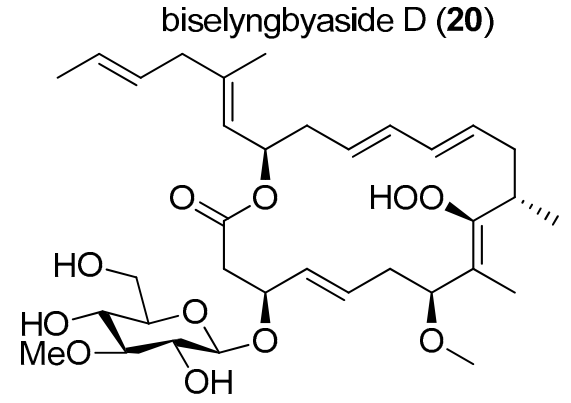

biselyngbyaside $F(22)$

Figure 4. Chemical structures of Compounds 17-24.

A novel 36-membered macrolactone, caylobolide A (25), was isolated from Bahamian cyanobacterium Lyngbya majuscula, which contains an unprecedented repeating unit, an adjoining pentad of 1,5-diols and a 1,3,5-triol (Figure 5). In vitro cytotoxicity assay showed that caylobolide A (25) possesses potent cytotoxicity against human colon tumor cells HCT-116 with an $\mathrm{IC}_{50}$ value of $9.9 \mu \mathrm{M}$ [20], and its total synthesis has been accomplished [36]. Caylobolide B (26) was isolated from the marine cyanobacterium Phormidium spp. collected from Key West, Florida, and it exhibits strong cytotoxicity against HT29 colorectal adenocarcinoma ( $\mathrm{IC}_{50}$ value of $4.5 \mu \mathrm{M}$ ) and HeLa cervical carcinoma cells ( $\mathrm{IC}_{50}$ value of $\left.12.2 \mu \mathrm{M}\right)$ [21]. 


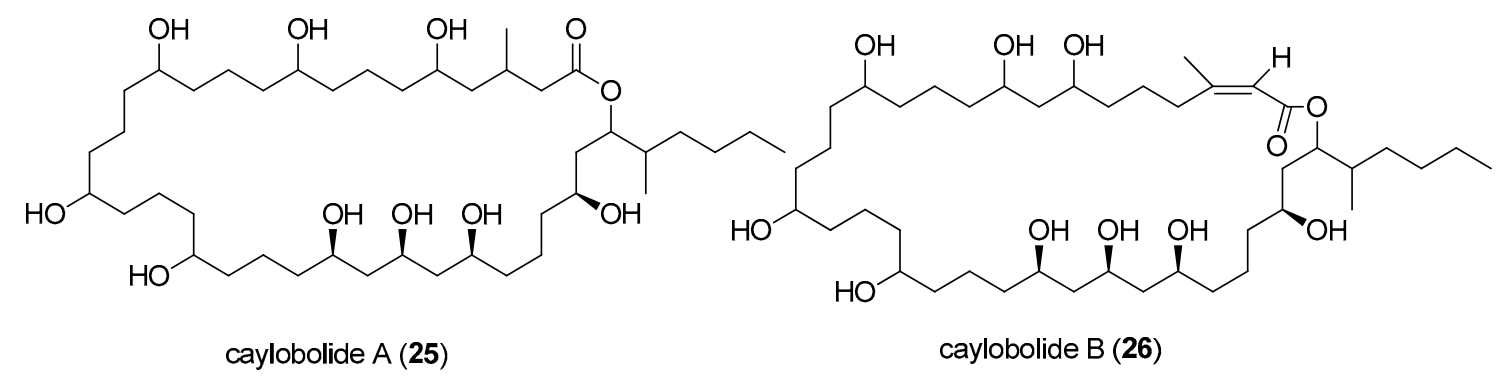

Figure 5. Chemical structures of Compounds 25 and 26.

Swinholide A (27), originally isolated from the marine sponge Theonella swinhoei, was isolated from the marine cyanobacterium $c f$. Symploca sp. collected from Fiji and was found to strongly inhibit the growth of several tumor cell lines with $\mathrm{IC}_{50}$ values ranging from $0.37 \mathrm{nM}$ to $1.0 \mu \mathrm{M}$ [22]. Two swinholide-based glycosylated macrolides, named ankaraholides A,B $(\mathbf{2 8 , 2 9 )}$, were isolated from two field collections of marine cyanobacteria (Figure 6). Ankaraholide A (28) exhibits strong antiproliferative activity against NCI-H460, Neuro-2a and MDA-MB-435 cell lines with $\mathrm{IC}_{50}$ values of 119, 262 and $8.9 \mathrm{nM}$, respectively. Ankaraholide A (28) inhibits proliferation of A-10 cells by inducing complete loss of the filamentous (F)-actin during the cell extending process when the concentration of ankaraholide A (28) reaches $30 \mathrm{nM}$ [22].

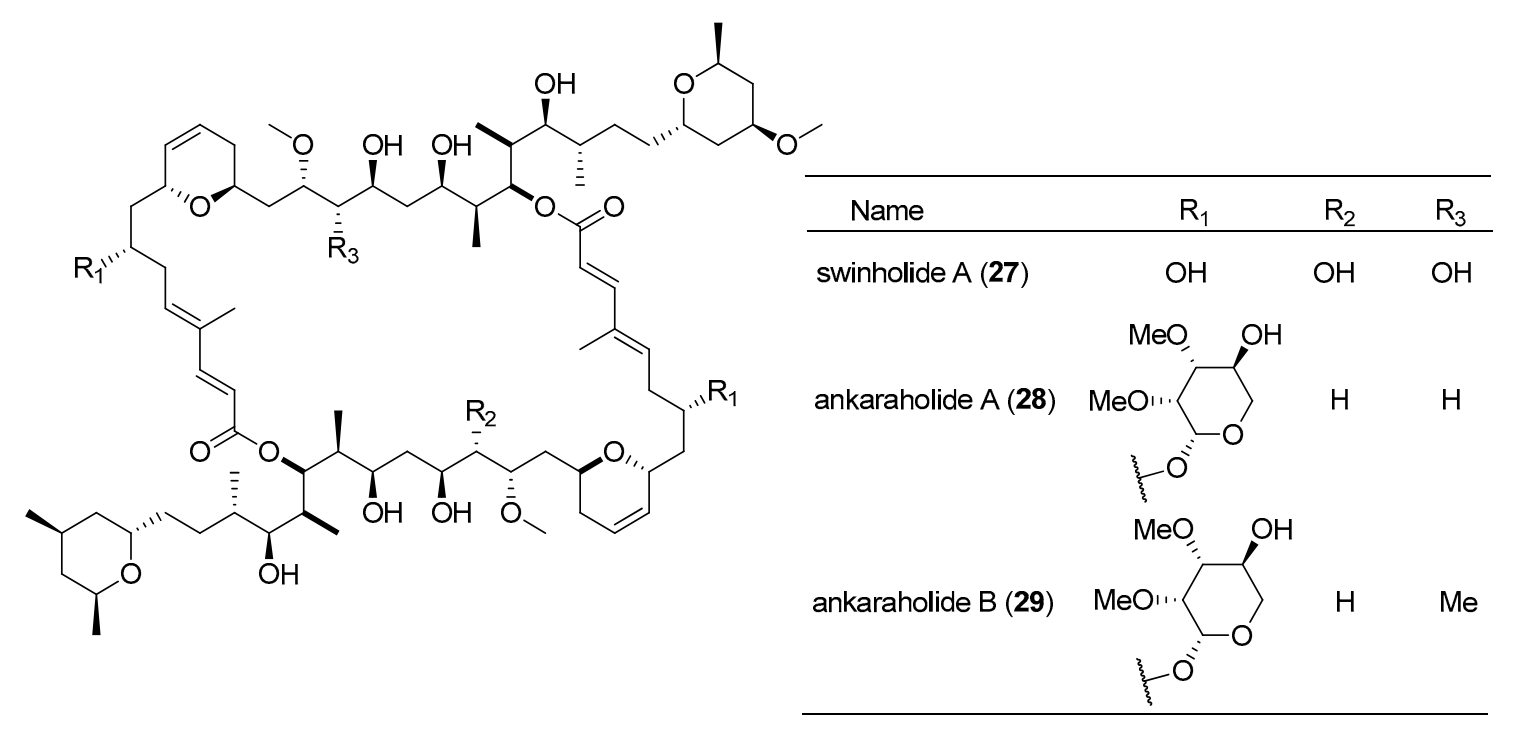

Figure 6. Chemical structures of Compounds 27-29.

A family of potent cytotoxic natural products, scytophycins A-E (30-34), was isolated from the terrestrial cyanobacterium Scytonema pseudohofmanni [37]. Scytophycins A (30) and B (31) display significant cytotoxicity against $\mathrm{KB}$ cells $\left(\mathrm{IC}_{50}\right.$ value of $1 \mathrm{ng} / \mathrm{mL}$ ), while scytophycins C-E (32-34) are less cytotoxic to $\mathrm{KB}$ cells $\left(\mathrm{IC}_{50}\right.$ values ranging from 10 to $100 \mathrm{ng} / \mathrm{mL}$ ) than scytophycin $\mathrm{A}$ (30) [23]. Total synthesis of scytophycin C (32) has been completed [38]. Screening of cyanobacteria leads to the discovery of three analogs of scytophycins, including 6-hydroxyscytophycin B (35), 19-O-demethylscytophycin C (36) and 6-hydroxy-7-O-methylscytophycin E (37) (Figure 7). These compounds (35-37) show strong inhibitory effect on the growth of KB (MIC values ranging from 1 to $5 \mathrm{ng} / \mathrm{mL}$ ) and LoVo cells (MIC values ranging from 10 to $50 \mathrm{ng} / \mathrm{mL}$ ) [23]. The cytotoxic tolytoxin (38) was isolated from terrestrial cyanobacterium Tolypothrix conglutinata, collected from Fanning Island [39], and displays excellent cytotoxicity against LoVo and $\mathrm{KB}$ cells with $\mathrm{IC}_{50}$ values of 8.4 and $5.3 \mathrm{nM}$, respectively [24]. 


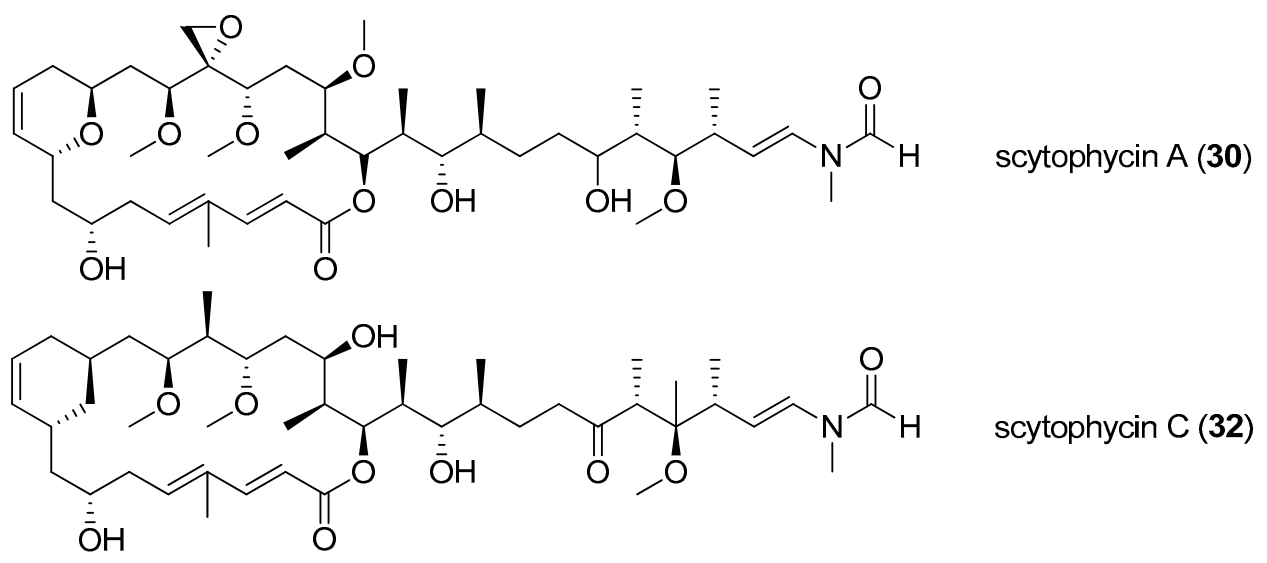

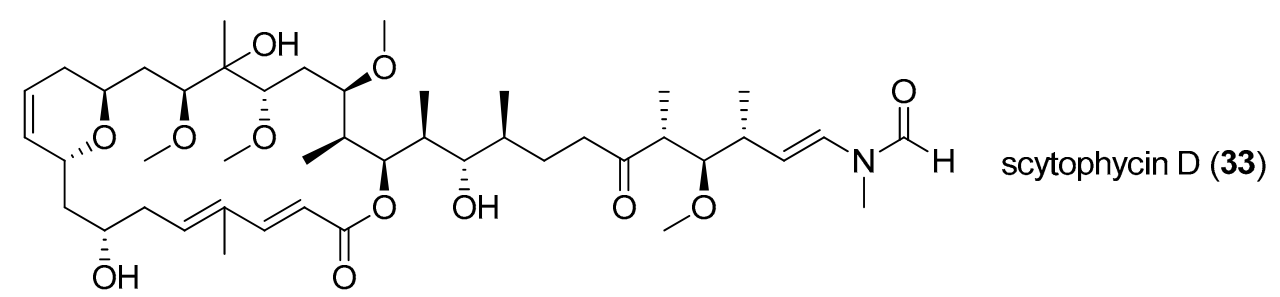

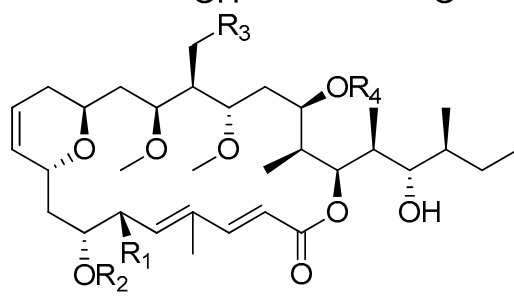
\begin{tabular}{llllll} 
Name & & & & \\
\hline scytophycin E (34) & $\mathrm{R}_{1}$ & $\mathrm{R}_{2}$ & $\mathrm{R}_{3}$ & $\mathrm{R}_{4}$ \\
\hline & $\mathrm{H}$ & $\mathrm{H}$ & $\mathrm{OH}$ & $\mathrm{Me}$
\end{tabular} 19-O-demethylscytophycin C (36) $\quad \mathrm{H} \quad \mathrm{H} \quad \mathrm{H} \quad \mathrm{H}$ 6-hydroxy-7-O-methylscytophycin $\mathrm{E}$ (37) $\mathrm{OH} \quad \mathrm{Me} \quad \mathrm{OH} \quad \mathrm{Me}$<smiles>[R]OC(=O)O[R17](=O)[O-]</smiles>

Figure 7. Chemical structures of Compounds 30-38.

Debromoaplysiatoxin (39) was isolated from the marine cyanobacterium Lyngbya majuscula, collected from Hawaii [40], and shows potent cytotoxicity against mouse lymphocytic leukemia P-388 [25]. Four analogs of debromoaplysiatoxin (39), including oscillatoxin A (40), 19,21-dibromooscillatoxin A (41), 19-bromoaplysiatoxin (42) and 21-bromooscillatoxin A (43), were isolated from a mixture of marine cyanobacteria Oscillatoria nigroviridis and Schizothrix calcicola from Enewetak Island (Figure 8). These compounds (41-43) contain the same 14-membered macrocycle as debromoaplysiatoxin (39), but they are bromine-containing macrolides [41]. A 14-membered glycosidic macrolide, lyngbouilloside (44), was isolated from the marine cyanobacterium Lyngbya bouillonii, harvested from Papua New Guinea. It displays a modest cytotoxicity against neuroblastoma cells with an $\mathrm{IC}_{50}$ value of $17 \mu \mathrm{M}$ [26]. Another 14-membered macrolide, koshikalide (45), was isolated from the marine cyanobacterium Lyngbya sp., collected from Mie Prefecture, Japan, and shows slight cytotoxicity against $\mathrm{HeLa} \mathrm{S}_{3}$ cells with an $\mathrm{IC}_{50}$ value of $42 \mu \mathrm{g} / \mathrm{mL}$ [27]. In addition, the total synthesis of koshikalide (45) has been achieved by exploiting a novel convergent strategy [42]. A 14-membered 
marine macrolide, sanctolide A (46), containing a rare $\mathrm{N}$-methyl enamide and a 2-hydroxyisovaleric acid, was obtained from the culture of cyanobacterium Oscillatoria sancta. It is cytotoxic against HT-29 and MDA-MB-435 cell lines [28], and its total synthesis was achieved [43].

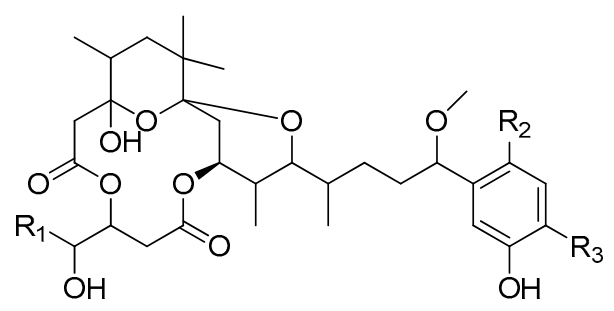

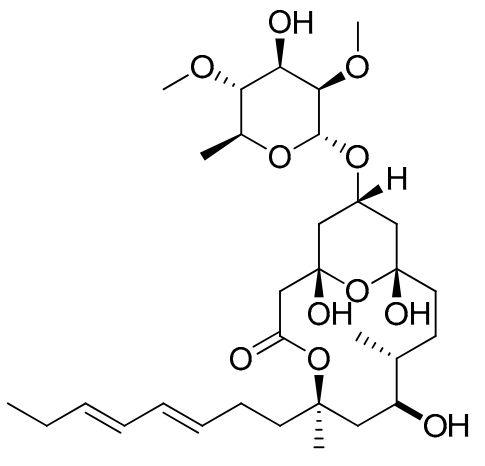

lyngbouilloside (44)

\begin{tabular}{lccc}
\hline Name & $\mathrm{R}_{1}$ & $\mathrm{R}_{2}$ & $\mathrm{R}_{3}$ \\
\hline debromoaplysiatoxin (39) & $\mathrm{Me}$ & $\mathrm{H}$ & $\mathrm{H}$ \\
oscillatoxin A (40) & $\mathrm{H}$ & $\mathrm{H}$ & $\mathrm{H}$ \\
19,21-dibromooscillatoxin A (41) & $\mathrm{H}$ & $\mathrm{Br}$ & $\mathrm{Br}$ \\
19-bromoaplysiatoxin (42) & $\mathrm{Me}$ & $\mathrm{Br}$ & $\mathrm{Br}$ \\
21-bromooscillatoxin A (43) & $\mathrm{H}$ & $\mathrm{Br}$ & $\mathrm{H}$ \\
\hline
\end{tabular}<smiles>CCC/C=C(/C)CC(=O)O[C@H](CO)CC(/C=C/CC/C=C\C(C)CC(=O)O[C@H](CCCCC)C[C@@H](CCC(C)C(=O)N(C)/C=C\CC(=O)OC(C(=O)O)C(C)C)OC)OC</smiles>

koshikalide (45)

sanctolide A (46)

Figure 8. Chemical structures of Compounds 39-46.

Two cytotoxic marcolides, acutiphycin (47) and 20,21-didehydroacutiphycin (48), were isolated from freshwater cyanobacterium Oscillatoria acutissima, collected from Manoa Valley, Oahu, and possess strong cytotoxicity against $\mathrm{KB}$ and NIH/3T3 cells $\left(\mathrm{ED}_{50}<1 \mu \mathrm{g} / \mathrm{mL}\right)$, as well as Lewis lung carcinoma [29]. A rare marine toxin, polycavernoside D (49), was obtained from the marine Okeania sp. collected from the Caribbean (Figure 9). The discovery of polycavernoside D, for the first time, provides a conclusive proof that these lethal toxins (polycavernosides) have, in fact, a cyanobacterial origin rather than other marine organisms. Polycavernoside D (49) displays cytotoxicity against the $\mathrm{H}-460$ human lung cancer cell line in a dose-dependent manner, with an $\mathrm{EC}_{50}$ value of $2.5 \mu \mathrm{M}$ [30]. Bastimolide A (50), isolated from the marine Okeania hirsuta from Bastimentos Park, Panama, is a rare 40-membered polyhydroxy macrolide consisting of one 1,3-diol, one 1,3,5-triol, six 1,5-diols and one tert-butyl group. Bastimolide A (50) exhibits strong cytotoxicity against Vero cells with an $\mathrm{IC}_{50}$ value of $2.1 \mu \mathrm{M}$ [31].

A rare 40-membered macrolactone, nuiapolide (51), was isolated from Niihau marine cyanobacterium. As a polyhydroxylated macrolide, nuiapolide (51) contains a rare tert-butyl carbinol residue, and it displays anti-chemotactic activity against Jurkat cells and cancerous $\mathrm{T}$ lymphocytes and can trigger a predominant $\mathrm{G} 2 / \mathrm{M}$ phase shift in the cell cycle [32]. 


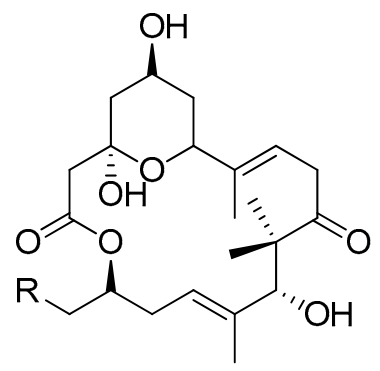

acutiphycin (47)

20,21-didehydroacutiphycin

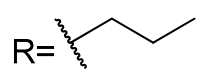

(48) $R=$

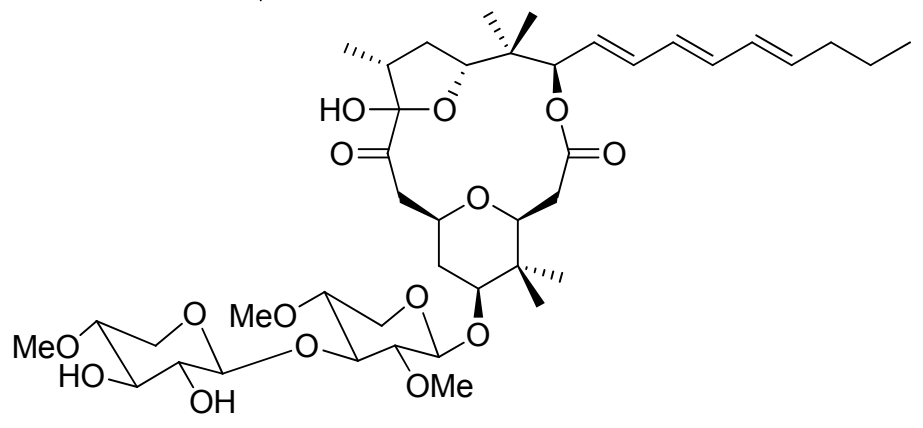
polycavernoside $\mathrm{D}(\mathbf{4 9})$

bastimolide $\mathrm{A}(\mathbf{5 0})$

nuiapolide (51)

Figure 9. Chemical structures of Compounds 47-51.

\section{Antibacterial Activity}

Some macrolides, such as erythromycin and azithromycin, have shown excellent antibacterial activity and are widely used in clinical practice of various types of bacterial infections [44]. Some macrolides from cyanobacteria also show good antibacterial activities. Cyanobacterium-derived macrolides with antimicrobial properties are listed in Table 2.

Scytophycins C-E (32-34) were isolated from the terrestrial cyanobacterium Scytonema pseudohofmanni, collected from Oahu, Hawaii, and were shown to exhibit weak antibacterial activity [37]. Three analogs of scytophycin C (32), including 6-hydroxyscytophycin B (35), 19-O-demethylscytophycin C (36) and 6-hydroxy-7-O-methylsctophycin E (37), were isolated from the cyanobacteria S. mirabile, S. burmanicurn and S. ocellatum, respectively. These macrolides (35-37) display antifungal activity against Aspergillus oryzae, Candida albicans, Penicillium notatum and Saccharomyces cerevisiae [23]. The cytotoxin, tolytoxin (38), was isolated from the terrestrial cyanobacterium Tolypothrix conglutinata, collected from Fanning Island [39], and was found to exhibit potent antifungal activity against various yeasts and filamentous fungi (MICs of $0.25-8 \mathrm{nM}$ ) [24]. 
Table 2. Antibacterial and antifungal macrolides.

\begin{tabular}{|c|c|c|c|c|c|}
\hline Metabolite & Source & Location & Target & Concentration/Effect & Reference \\
\hline $\begin{array}{l}\text { 6-hydroxyscytophycin } \\
\text { B (35) }\end{array}$ & Scytonema mirabile & cultured & $\begin{array}{l}\text { Fungus (1) Aspergillus oryzae } \\
\text { (2) Candida albicans } \\
\text { (3) Penicillium notatum } \\
\text { (4) Saccharomyces cerevisiae }\end{array}$ & $\mathrm{nd}^{\mathrm{a}}$ & [23] \\
\hline $\begin{array}{c}19-O \\
\text {-demethylscytophycin } \\
\text { C (36) }\end{array}$ & Scytonema burmanicurn & cultured & $\begin{array}{l}\text { Fungus (1) Aspergillus oryzae } \\
\text { (2) Candida albicans } \\
\text { (3) Penicillium notatum } \\
\text { (4) Saccharomyces cerevisiae }\end{array}$ & $\mathrm{nd}^{\mathrm{a}}$ & [23] \\
\hline $\begin{array}{c}\text { 6-hydroxy-7-O } \\
\text {-methylscytophycin } \\
\text { E (37) }\end{array}$ & Scytonema ocellatum & cultured & $\begin{array}{l}\text { Fungus (1) Aspergillus oryzae } \\
\text { (2) Candida albicans } \\
\text { (3) Penicillium notatum } \\
\text { (4) Saccharomyces cerevisiae }\end{array}$ & $\mathrm{nd}^{\mathrm{a}}$ & [23] \\
\hline tolytoxin (38) & $\begin{array}{l}\text { Tolypothrix conglutinata } \\
\text { var. colorata }\end{array}$ & $\begin{array}{l}\text { Fanning } \\
\text { Island }\end{array}$ & $\begin{array}{l}\text { Fungi Penicillium notatum } \\
\text { and Rhizoctonia solani } 1165\end{array}$ & $\begin{array}{l}\text { MIC value of } 0.25 \mathrm{nM} \\
\text { respectively }\end{array}$ & [24] \\
\hline $\begin{array}{c}\text { 7-OMe-scytophycin } \\
\text { B (52) }\end{array}$ & Anabaena sp. & cultured & $\begin{array}{l}\text { Fungus Candida albicans } \\
\text { HAMBI } 484 \text { and Candida } \\
\text { guilliermondii HAMBI } 257\end{array}$ & $\begin{array}{c}\text { MIC values of } 0.40 \text { and } \\
0.80 \text { mM respectively; } \\
\mathrm{IC}_{50} \text { value of } 0.19 \text { and } \\
0.23 \mu \mathrm{M} \text { respectively }\end{array}$ & [45] \\
\hline amantelide A (53) & Oscillatoriales & Guam & $\begin{array}{l}\text { Fungi Lindra thalassiae and } \\
\text { Fusarium sp. }\end{array}$ & $\begin{array}{l}\text { totally inhibited of } \\
\quad 62.5 \mu \mathrm{g} / \mathrm{mL}\end{array}$ & [46] \\
\hline amantelide B (54) & Oscillatoriales & Guam & Fungus Dendryphiella salina & $\begin{array}{l}\text { totally inhibited of } \\
\quad 6.25 \mu \mathrm{g} / \mathrm{mL}\end{array}$ & {$[46]$} \\
\hline
\end{tabular}

a Not determined.

A bioactive marcolide, 7-OMe-scytophycin B (52), was identified from a culture of a marine cyanobacterium and was found to exhibit antifungal activity against Candida albicans HAMbI 484 and Candida guilliermondii HAMBI 257 with MIC values of 0.40 and $0.80 \mathrm{mM}$ and $\mathrm{IC}_{50}$ values of 0.19 and $0.23 \mathrm{mM}$, respectively [45]. Two 40-membered macrolactones, amantelides A,B $(\mathbf{5 3}, \mathbf{5 4})$, are composed of a 1,3-diol and contiguous 1,5-diol units and a tert-butyl substituent. These compounds were isolated from a Guam cyanobacterium belonging to the family Oscillatoriales (Figure 10). Amantelide A (53) shows a broad spectrum of inhibitory effects on the growth of both eukaryotic and prokaryotic cells. The growth of the fungi Lindra thalassiae and Fusarium sp. is completely inhibited when the concentration of amantelide A (53) is $62.5 \mu \mathrm{g} / \mathrm{mL}$. When the concentration of amantelide B (54) is $6.25 \mu \mathrm{g} / \mathrm{mL}$, the growth of the fungus Dendryphiella salina is completely inhibited [46].

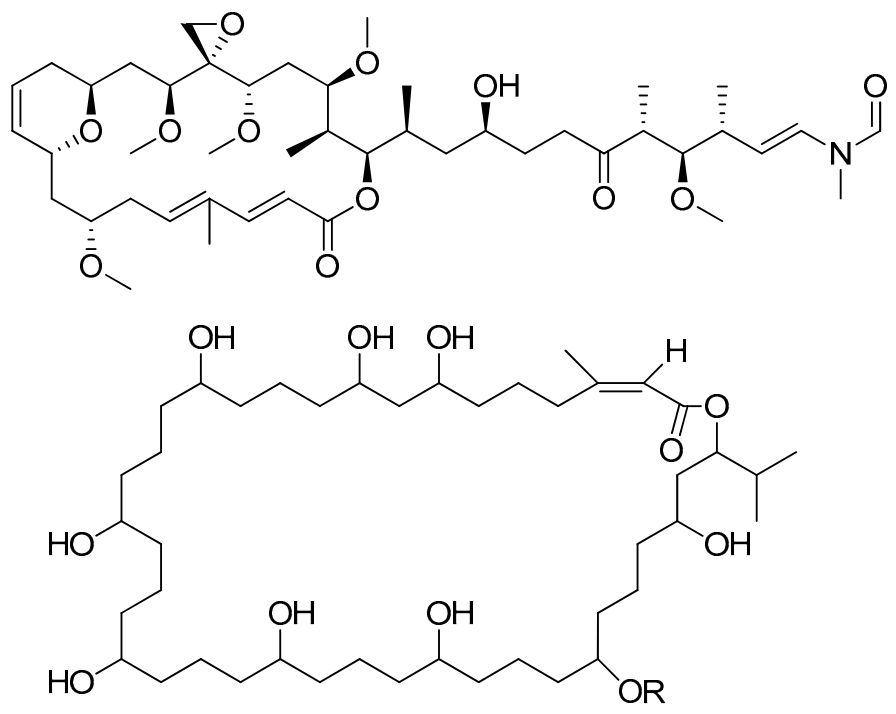

Figure 10. Chemical structures of Compounds 52-54. 


\section{Effects of Cyanobacterium-Derived Macrolides on Animals}

Toxin-producing cyanobacterial blooms are a potential health risk for other living organisms, including humans [47]. Cyanobacterium-derived macrolides show toxicity to animals, such as brine shrimp and mice. The effects of cyanobacterium-derived macrolides on fauna are described in Table 3.

Table 3. Effects of cyanobacterium-derived macrolides on animals.

\begin{tabular}{|c|c|c|c|c|c|}
\hline Metabolite & Source & Location & Target Fauna & Impacts & Reference \\
\hline lyngbyabellin A (1) & $\begin{array}{l}\text { Lyngbya } \\
\text { majuscula }\end{array}$ & Guam & mice & $\begin{array}{l}\mathrm{LD}_{50} \text { value of } \\
1.2-1.5 \mathrm{mg} / \mathrm{kg}\end{array}$ & [6] \\
\hline tolytoxin (38) & $\begin{array}{c}\text { Scytonema } \\
\text { pseudohofmanni }\end{array}$ & cultured & mice & $\begin{array}{l}\mathrm{LD}_{50} \text { value of } \\
1.5 \mathrm{mg} / \mathrm{kg}\end{array}$ & [24] \\
\hline sanctolide A (48) & $\begin{array}{l}\text { Oscillatoria } \\
\text { sancta }\end{array}$ & cultured & brine shrimp & $\begin{array}{l}\mathrm{LD}_{50} \text { value of } \\
23.5 \mu \mathrm{M}\end{array}$ & [28] \\
\hline gloeolactone (55) & Gloeotrichia sp. & $\begin{array}{c}\text { Clark Canyon } \\
\text { Reservoir }\end{array}$ & brine shrimp & $\begin{array}{c}100 \% \text { killed at } \\
125 \mu \mathrm{g} / \mathrm{mL}\end{array}$ & [48] \\
\hline phormidolide (56) & Phormidium sp. & $\begin{array}{l}\text { Sulawesi, } \\
\text { Indonesia }\end{array}$ & brine shrimp & $\begin{array}{c}\mathrm{LD}_{50} \text { value of } \\
1.5 \mu \mathrm{M}\end{array}$ & [49] \\
\hline cyanolide A (57) & $\begin{array}{l}\text { Lyngbya } \\
\text { bouillonii }\end{array}$ & $\begin{array}{l}\text { Papua New } \\
\text { Guinea }\end{array}$ & $\begin{array}{c}\text { snail vector } \\
\text { Biomphalaria glabrata }\end{array}$ & $\begin{array}{c}\mathrm{LD}_{50} \text { value of } \\
1.2 \mu \mathrm{M}\end{array}$ & [50] \\
\hline
\end{tabular}

The cytotoxic macrolactone, lyngbyabellin A (1), exhibits potent toxicity to mice in vivo trials (lethal dose of 2.4 to $8.0 \mathrm{mg} / \mathrm{kg}$; sublethal dose of 1.2 to $1.5 \mathrm{mg} / \mathrm{kg}$ ) [6]. Tolytoxin (38) is highly toxic to mice with a sublethal dose (ip) of $1.5 \mathrm{mg} / \mathrm{kg}$ [24].

A 14-membered macrolide, sanctolide A (48), shows high toxicity toward the brine shrimp with an $\mathrm{LC}_{50}$ value of $23.5 \mu \mathrm{M}$ [28]. A 10-membered ring macrolide, gloeolactone (55), was isolated from the cyanobacterium Gloeotrichia sp., harvested in Clark Canyon Reservoir (Figure 11). Gloeolactone (55) exhibits weak toxicity to brine shrimp. All brine shrimps are dead when the concentration of gloeolactone (55) is $125 \mu \mathrm{g} / \mathrm{mL}$ [48]. Phormidolide (56) was isolated from the marine cyanobacterium Phormidium sp. cultured in Indonesia and was found to exhibit very high toxicity ( $\mathrm{LC}_{50}$ value of $1.5 \mu \mathrm{M})$ in the brine shrimp test [49].
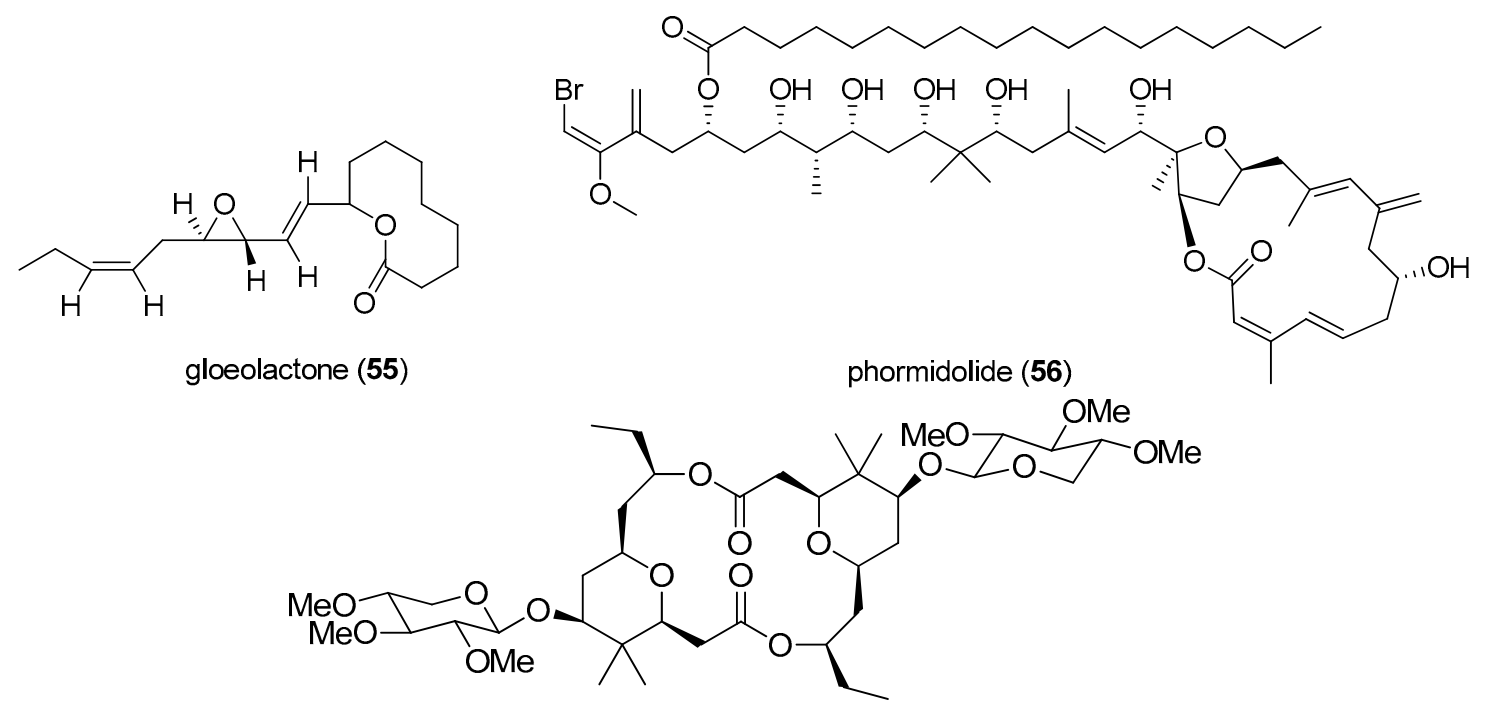

cyanolide A (57)

Figure 11. Chemical structures of Compounds 55-57. 
A symmetrical macrolide dimer, cyanolide A (57), was obtained from the marine cyanobacterium Lyngbya bouillonii collected from Papua New Guinea. Cyanolide A (57) displays potent molluscicidal activity against the snail vector Biomphalaria glabrata with an $\mathrm{LC}_{50}$ value of $1.2 \mu \mathrm{M}$. Cyanolide A (57) can be used as a new, potent molluscicidal agent to effectively control the spread of schistosomiasis [50]. Its total synthesis has been accomplished [51].

\section{Other Bioactivity}

Cyanobacterium-derived macrolides with rich chemical diversity show various important bioactivities (Table 4). The macrolide biselyngbyaside (17), isolated from the marine cyanobacterium Lyngbya sp., has been investigated for its effects on osteoclast differentiation and function. Biselyngbyaside (17) inhibits RANKL-induced osteoclastogenesis by inhibiting the expression of c-Fos and NFATc1 in mouse monocytic RAW264 cells. Therefore, biselyngbyaside (17) is a potentially promising compound with therapeutic and preventive activities against bone-lytic diseases [52]. A toxic cyanobacterial macrolide, debromoaplysiatoxin (39), has been found to cause severe cutaneous inflammation in humans and other animals after topical application [25].

Table 4. Other bioactivity of cyanobacterium-derived macrolides.

\begin{tabular}{|c|c|c|c|c|}
\hline Metabolite & Source & Location & Biological Activity & Reference \\
\hline biselyngbyaside (17) & Lyngbya sp. & $\begin{array}{c}\text { Okinawa } \\
\text { Prefecture Japan }\end{array}$ & $\begin{array}{l}\text { osteoclast differentiation } \\
\text { and function }\end{array}$ & [52] \\
\hline debromoaplysiatoxin (39) & Lyngbya majuscula & $\begin{array}{l}\text { Enewetak Atoll, } \\
\text { Marshall Islands }\end{array}$ & $\begin{array}{l}\text { produce an irritant pustular } \\
\text { folliculitis in humans and cause a } \\
\text { severe cutaneous inflammatory } \\
\text { reaction in the rabbit and in } \\
\text { hairless mice }\end{array}$ & [25] \\
\hline bastimolide A (50) & Okeania hirsuta & $\begin{array}{l}\text { Caribbean coast } \\
\text { of Panama }\end{array}$ & $\begin{array}{c}\text { Plasmodium falciparum TM90-C2A, } \\
\text { TM90-C2B, W2, TM91-C235 (IC } 50 \\
\text { values of } 80,90,140 \text { and } \\
270 \mathrm{nM} \text { respectively) }\end{array}$ & [31] \\
\hline malyngolide dimer (58) & Lyngbya majuscula & Panama & $\begin{array}{c}\text { Plasmodium falciparum }\left(\mathrm{IC}_{50} \text { values }\right. \\
\text { of } 19 \mu \mathrm{M})\end{array}$ & [53] \\
\hline tanikolide dimer (59) & Lyngbya majuscula & Madagascar & SIRT2 $\left(\mathrm{IC}_{50}=176 \mathrm{nM}\right.$ to $\left.2.4 \mu \mathrm{M}\right)$ & [54] \\
\hline palmyrolide A (60) & $\begin{array}{l}\text { Leptolyngbya cf. } \\
\text { Oscillatoria sp. }\end{array}$ & Palmyra Atoll & $\begin{array}{l}\text { suppression of calcium influx in } \\
\text { cerebrocortical neurons ( } \mathrm{IC}_{50} \\
\text { value of } 3.70 \mu \mathrm{M}) \text { sodium channel } \\
\text { blocking activity in neuro-2a cells } \\
\quad\left(\mathrm{IC}_{50} \text { value of } 5.2 \mu \mathrm{M}\right)\end{array}$ & [55] \\
\hline cocosolide $(\mathbf{6 1})$ & Symploca sp. & Guam & $\begin{array}{l}\text { inhibition of IL-2 production and } \\
\text { T-cell proliferation }\end{array}$ & [7] \\
\hline
\end{tabular}

A rare 40-membered polyhydroxy macrolide, bastimolide A (50), exhibits high selectivity and antimalarial activity against four drug-resistant malaria parasite strains, including TM90-C2A, TM90-C2B, W2 and TM91-C235, with $\mathrm{IC}_{50}$ values of 80, 90, 140 and $270 \mathrm{nM}$, respectively. It has been proven that bastimolide A (50) is a potentially promising antimalarial lead compound with high selectivity and antimalarial activity against drug-resistant strains [31]. Malyngolide dimer (58) was isolated from the marine cyanobacterium Lyngbya majuscula collected from Panama and was shown to exhibit moderate antimalarial activity against chloroquine-resistant Plasmodium falciparum (W2) with an $\mathrm{IC}_{50}$ value of $19 \mu \mathrm{M}$ [53].

A novel SIRT2-selective inhibitor, tanikolide dimer (59), was isolated from marine cyanobacterium Lyngbya majuscula collected from Madagascar, and it possesses a symmetrical dimer, which has been elucidated by comparison of the natural and synthetic stereoisomers using chiral GC-MS (Figure 12). The tanikolide dimer (59) is a potent and selective SIRT2 inhibitor with an $\mathrm{IC}_{50}$ value of $176 \mathrm{nM}$ [54]. 
<smiles>CCCCCCCCC[C@H](CCC(C)C(=O)OCC(CO)(CCCCCCCCC)CC(C)C(=O)O)OCC(C)(C)C</smiles>

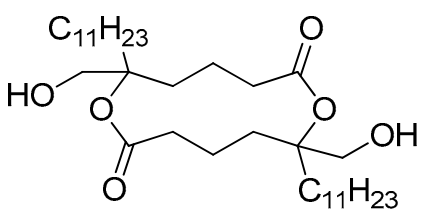

tanikolide dimer (59)<smiles>CCC(C)CC/C=C/N(C)C(=O)CCCC(C)CC(C)C(C)(C)C</smiles>

palmyrolide $A(60)$

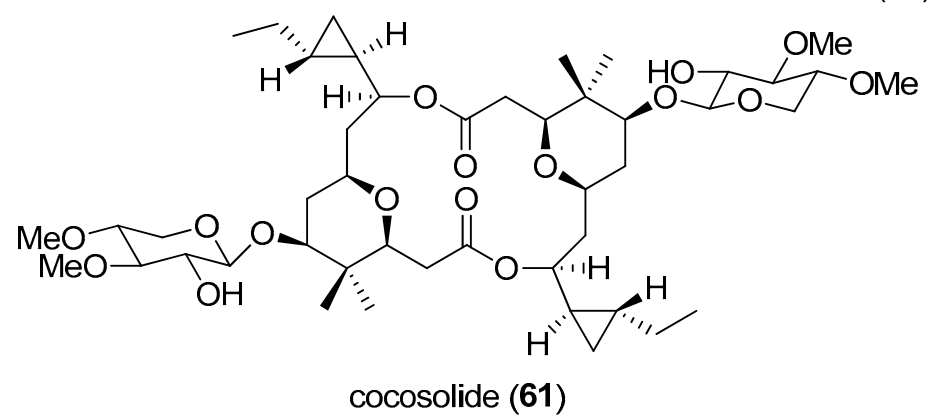<smiles>[R]C1CCC(C)CC(OC(=O)CC=CN(C)C(=O)C(C)C)C(C)(C)C1</smiles>

laingolide (62) $\quad \mathrm{R}=\mathrm{H}$<smiles>CC(C)CCC(C)CC(OC(=O)C(C)CC/C=C\CCC(C)C(=O)N(C)C)C(C)(C)C</smiles>

madangolide (64)

laingolide $A(63) R=M e$

Figure 12. Chemical structures of Compounds 58-64.

An unusually stabilized neuroactive macrolide, palmyrolide $\mathrm{A}(\mathbf{6 0})$, was isolated, via an assay-based screening program for new neuroactive compounds from cyanobacteria Leptolyngbya $c f$. and Oscillatoria spp. harvested in Palmyra Atoll. Palmyrolide A (60) contains a rare $\mathrm{N}$-methyl enamide and an intriguing tert-butyl group, and it can potently inhibit $\mathrm{Ca}^{2+}$ oscillations in murine cerebrocortical neuronal cells with an $\mathrm{IC}_{50}$ value of $3.70 \mu \mathrm{M}$. Moreover, palmyrolide A (60) can significantly block the sodium channel activity of neuro-2a cells ( $\mathrm{IC}_{50}$ value of $5.2 \mu \mathrm{M}$ ) without appreciable cytotoxicity. The above intriguing experimental results suggest that palmyrolide A (60) could be a promising drug candidate for further pharmacological exploration [55], and its total synthesis has been completed [56].

A dimeric macrolide, cocosolide (61), was isolated from the marine cyanobacterium Symploca sp. from Guam, and it strongly inhibits IL-2 production in both T-cell receptor-dependent and independent manners. Both the presence of the sugar moiety and the integrity of the dimeric structure ensure the functionality of cocosolide (61). In addition, the total synthesis of cocosolide (61) has been accomplished [7].

Three novel nitrogen-containing macrolides, laingolide (62) [57], laingolide A (63) and madangolide (64) [58], have been identified from the marine cyanobacterium Lyngbya bouillonii harvested in Laing Island, Papua-New Guinea (Figure 12). The structures of these macrolides (62-64) contain a lactone ring of 15,15 and 17 members, respectively [58].

\section{Conclusions}

Cyanobacteria are rich sources of various natural products with unprecedented pharmacological and biological activities. Up to the end of 2016, a total of 64 macrolide compounds have been isolated from cyanobacteria, including 49 macrolides from marine cyanobacteria and 15 macrolides 
from terrestrial cyanobacteria. More than half of the cyanobacterium-derived macrolides, a total of 36 compounds, were isolated from the cyanobacterial genus Lyngbya species, particularly from Lyngbya majuscula. Most of these cyanobacterium-derived macrolides possess several noticeable bioactivities, including antitumor, antibacterial and antimalarial. The overwhelming majority of cyanobacteria derived macrolides (1-51) display in vitro antitumor activity. Secondary metabolites of cyanobacteria are widely evaluated for their antitumor effects since many metabolites of cyanobacteria have exhibited potent antitumor activities. Some of these macrolides, including tolytoxin (38), bastimolide A (50) and tanikolide dimer (59), exhibited surprisingly strong bioactivity, thus representing potential new drug lead compounds, which are worthy of further research on synthesis and pharmacological activity. The total synthesis of 10 bioactive macrolides, such as cocosolide, has been achieved with a great deal of efforts. The research on the total synthesis of macrolides will promote pharmacologic research and create new opportunities to undertake research in drug discovery, medicine design and large-scale manufacturing. At present, three scholars, including Luesch, Moore and Gerwick, have greatly contributed to the discovery of new macrolides from cyanobacteria. Cyanobacteria have great potentials as sustainable sources for the production of bioactive metabolites because of their rapid growth, genetic tractability and cultivable property. Although cyanobacteria possess the cultivable properties similar to those of microorganisms, cyanobacteria have attracted far less attention than microorganisms. More efforts should be devoted to improving the production of bioactive metabolites in cyanobacteria via cultivation design, metabolic engineering together with efficient isolation. In addition, the programs for drug discovery from cyanobacteria, including the Panama International Cooperative Biodiversity Group (ICGB) program, might facilitate and enhance drug discovery from cyanobacteria. A systematic review on macrolides from cyanobacteria would help establish an effective support system for the discovery and development of cyanobacterium-derived macrolides, and such a support system could also facilitate collection, purification and identification of bioactive macrolides, leading to improve bioactivity assay, synthesis, data analysis and information technology.

Acknowledgments: This work was financially supported by the National Natural Science Foundation of China (41406163), the 863 Program of China (2013AA092902), the Ningbo Marine Algae Biotechnology Team (2011B81007), the Li Dak Sum Yip Yio Chin Kenneth Li Marine Biopharmaceutical Development Fund, the National 111 Project of China, the Scientific Research Foundation for Returned Scholars of ZJHRSS and the K.C. Wong Magna Fund in Ningbo University.

Conflicts of Interest: The authors declare no conflict of interest.

\section{References}

1. Capper, A.; Erickson, A.A.; Ritson-Williams, R.; Becerro, M.A.; Arthur, K.A.; Paul, V.J. Palatability and chemical defences of benthic cyanobacteria to a suite of herbivores. J. Exp. Mar. Biol. Ecol. 2016, 474, 100-108. [CrossRef]

2. Tan, L.T. Bioactive natural products from marine cyanobacteria for drug discovery. Phytochemistry 2007, 68, 954-979. [CrossRef] [PubMed]

3. Napolitano, J.G.; Daranas, A.H.; Norte, M.; Fernández, J.J. Marine macrolides, a promising source of antitumor compounds. Anti-Cancer Agent Med. Chem. 2009, 9, 122-137. [CrossRef]

4. Kollár, P.; Rajchard, J.; Balounová, Z.; Pazourek, J. Marine natural products: bryostatins in preclinical and clinical studies. Pharm. Biol. 2014, 52, 237-242. [CrossRef] [PubMed]

5. Belakhov, V.V.; Garabadzhiu, A.V. Polyene macrolide antibiotics: mechanisms of inactivation, ways of stabilization, and methods of disposal of unusable drugs (review). Russ. J. Gen. Chem. 2015, 85, $2985-3001$. [CrossRef]

6. Luesch, H.; Yoshida, W.Y.; Moore, R.E.; Paul, V.J.; Mooberry, S.L. Isolation, structure determination, and biological activity of lyngbyabellin A from the marine cyanobacterium Lyngbya majuscula. J. Nat. Prod. 2000, 63, 611-615. [CrossRef] [PubMed] 
7. $\quad$ Gunasekera, S.P.; Li, Y.; Ratnayake, R.; Luo, D.M.; Lo, J.; Reibenspies, J.H.; Xu, Z.S.; Clare-Salzler, M.J.; Ye, T.; Paul, V.J.; Luesch, H. Discovery, total synthesis and key structural elements for the immunosuppressive activity of cocosolide, a symmetrical glycosylated macrolide dimer from marine cyanobacteria. Chem. Eur. J. 2016, 22, 8158-8166. [CrossRef] [PubMed]

8. Klein, D.; Braekman, J.C.; Daloze, D.; Hoffmann, L.; Demoulin, V. Lyngbyaloside, a novel 2,3,4-Tri-O-methyl-6-deoxy-r-mannopyranoside macrolide from Lyngbya bouillonii (Cyanobacteria). J. Nat. Prod. 1997, 60, 1057-1059. [CrossRef]

9. DeVita, V.T.J.; Rosenberg, S.A. Two hundred years of cancer research. N. Engl. J. Med. 2012, 366, $2207-2214$. [CrossRef] [PubMed]

10. Luesch, H.; Yoshida, W.Y.; Moore, R.E.; Paul, V.J. Isolation and structure of the cytotoxin lyngbyabellin B and absolute configuration of lyngbyapeptin A from the marine cyanobacterium Lyngbya majuscula. J. Nat. Prod. 2000, 63, 1437-1439. [CrossRef] [PubMed]

11. Han, B.N.; McPhail, K.L.; Gross, H.; Goeger, D.E.; Mooberry, S.L.; Gerwick, W.H. Isolation and structure of five lyngbyabellin derivatives from a Papua New Guinea collection of the marine cyanobacterium Lyngbya majuscula. Tetrahedron 2005, 61, 11723-11729. [CrossRef]

12. Choi, H.; Mevers, E.; Byrum, T.; Valeriote, F.A.; Gerwick, W.H. Lyngbyabellins K-N from Two Palmyra Atoll Collections of the marine cyanobacterium Moorea bouillonii. Eur. J. Org. Chem. 2012, 5141-5150. [CrossRef] [PubMed]

13. Luesch, H.; Yoshida, W.Y.; Harrigan, G.G.; Doom, J.P.; Moore, R.E.; Paul, V.J. Lyngbyaloside B, a new glycoside macrolide from a palauan marine cyanobacterium, Lyngbya sp. J. Nat. Prod. 2002, 65, 1945-1948. [CrossRef] [PubMed]

14. Matthew, S.; Salvador, L.A.; Schupp, P.J.; Paul, V.J.; Luesch, H. Cytotoxic halogenated macrolides and modified peptides from the apratoxin-producing marine cyanobacterium Lyngbya bouillonii from Guam. J. Nat. Prod. 2010, 73, 1544-1552. [CrossRef] [PubMed]

15. Teruya, T.; Sasaki, H.; Kitamura, K.; Nakayama, T.; Suenaga, K. Biselyngbyaside, a macrolide glycoside from marine cyanobacterium Lyngbya sp. Org. Lett. 2009, 11, 2421-2424. [CrossRef] [PubMed]

16. Morita, M.; Ohno, O.; Teruya, T.; Yamori, T.; Inuzuka, T.; Suenaga, K. Isolation and structures of biselyngbyasides B, C, and D from the marine cyanobacterium Lyngbya sp., and the biological activities of biselyngbyasides. Tetrahedron 2012, 68, 5984-5990. [CrossRef]

17. Watanabe, A.; Ohno, O.; Morita, M.; Inuzuka, T.; Suenaga, K. Structures and biological activities of novel biselyngbyaside analogs isolated from the marine cyanobacterium Lyngbya sp. Bull. Chem. Soc. Jpn. 2015, 88, 1256-1264. [CrossRef]

18. Morita, M.; Ohno, O.; Suenaga, K. Biselyngbyolide A, a novel cytotoxic macrolide from the marine cyanobacterium Lyngbya sp. Chem. Lett. 2012, 41, 165-167. [CrossRef]

19. Ohno, O.; Watanabe, A.; Morita, M.; Suenaga, K. Biselyngbyolide B, a novel ER stress-inducer isolated from the marine cyanobacterium Lyngbya sp. Chem. Lett. 2014, 43, 287-289. [CrossRef]

20. MacMillan, J.B.; Molinski, T.F. Caylobolide A, a unique 36-membered macrolactone from a Bahamian Lyngbya majuscula. Org. Lett. 2002, 4, 1535-1538. [CrossRef] [PubMed]

21. Salvador, L.A.; Paul, V.J.; Luesch, H. Caylobolide B, a macrolactone from symplostatin 1-producing marine cyanobacteria phormidium spp. from Florida. J. Nat. Prod. 2010, 73, 1606-1609. [CrossRef] [PubMed]

22. Andrianasolo, E.H.; Gross, H.; Goeger, D.; Musafija-Girt, M.; McPhail, K.; Leal, R.M.; Mooberry, S.L.; Gerwick, W.H. Isolation of swinholide A and related glycosylated derivatives from two field collections of marine cyanobacteria. Org. Lett. 2005, 7, 1375-1378. [CrossRef] [PubMed]

23. Carmeli, S.; Moore, R.E.; Patterson, G.M.L. Tolytoxin and new scytophycins from three species of Scytonema. J. Nat. Prod. 1990, 53, 1533-1542. [CrossRef] [PubMed]

24. Patterson, G.M.L.; Carmeli, S. Biological effects of tolytoxin (6-hydroxy-7-O-methyl-scytophycin b), a potent bioactive metabolite from cyanobacteria. Arch. Microbiol. 1992, 157, 406-410. [CrossRef] [PubMed]

25. Mynderse, J.S.; Moore, R.E.; Kashiwagi, M.; Norton, T.R. Antileukemia activity in the Osciliatoriaceae: Isolation of debromoaplysiatoxin from Lyngbya. Science 1977, 196, 538-540. [CrossRef] [PubMed]

26. Tan, L.T.; Márquez, B.L.; Gerwick, W.H. Lyngbouilloside, a novel glycosidic macrolide from the marine cyanobacterium Lyngbya bouillonii. J. Nat. Prod. 2002, 65, 925-928. [CrossRef] [PubMed]

27. Iwasaki, A.; Teruya, T.; Suenaga, K. Isolation and structure of koshikalide, a 14-membered macrolide from the marine cyanobacterium Lyngbya sp. Tetrahedron Lett. 2010, 51, 959-960. [CrossRef] 
28. Kang, H.S.; Krunic, A.; Orjala, J. Sanctolide A, a 14-membered PK-NRP hybrid macrolide from the cultured cyanobacterium Oscillatoria sancta (SAG 74.79). Tetrahedron Lett. 2012, 53, 3563-3567. [CrossRef] [PubMed]

29. Barchi, J.J.; Moore, R.E.; Patterson, G.M.L. Acutiphycin and 20,21-didehydroacutiphycin, new antineoplastic agents from the cyanophyte Oscillatoria acutissima. J. Am. Chem. Soc. 1984, 106, 8193-8197. [CrossRef]

30. Navarro, G.; Cummings, S.; Lee, J.; Moss, N.; Glukhov, E.; Valeriote, F.A.; Gerwick, L.; Gerwick, W.H. Isolation of polycavernoside D from a marine cyanobacterium. Environ. Sci. Technol. Lett. 2015, 2, 166-170. [CrossRef]

31. Shao, C.L.; Linington, R.G.; Balunas, M.J.; Centeno, A.; Boudreau, P.; Zhang, C.; Engene, N.; Spadafora, C.; Mutka, T.S.; Kyle, D.E.; Gerwick, L.; Wang, C.Y.; Gerwick, W.H. Bastimolide A, a potent antimalarial polyhydroxy macrolide from the marine cyanobacterium Okeania hirsute. J. Org. Chem. 2015, 80, 7849-7855. [CrossRef] [PubMed]

32. Mori, S.; Williams, H.; Cagle, D.; Karanovich, K.F.; Horgen, D.; Smith, R.; Watanabe, C.M.H. Macrolactone nuiapolide, isolated from a Hawaiian marine cyanobacterium, exhibits anti-chemotactic activity. Mar. Drugs 2015, 13, 6274-6290. [CrossRef] [PubMed]

33. Fuwa, H.; Yamagata, N.Y.; Okuaki, Y.T.; Ogata, Y.Y.; Saito, A.; Sasaki, M. total synthesis and complete stereostructure of a marine macrolide glycoside, (-)-lyngbyaloside B. Chem. Eur. J. 2016, 22, 6815-6829. [CrossRef] [PubMed]

34. Chang, C.; Stefan, E.; Taylo, R.E. Total synthesis and structural reassignment of lyngbyaloside C highlighted by intermolecular ketene esterification. Chem. Eur. J. 2015, 21, 10681-10686. [CrossRef] [PubMed]

35. Chandrasekhar, S.; Rajesh, G.; Naresh, T. Enantioselective synthesis of the C5-C23 segment of biselyngbyaside. Tetrahedron Lett. 2013, 54, 252-255. [CrossRef]

36. Yadav, J.S.; Swapnil, N.; Venkatesh, M.; Prasad, A.R. Studies directed toward the synthesis of caylobolide A: convergent synthesis of C21-C40 subunit. Tetrahedron Lett. 2014, 55, 1164-1167. [CrossRef]

37. Ishibashi, M.; Moore, R.E.; Patterson, G.M.L. Scytophycins, cytotoxic and antimycotic agents from the cyanophyte Scytonema pseudohofmanni. J. Org. Chem. 1986, 51, 5300-5306. [CrossRef]

38. Cui, J.; Watanabe, T.; Shibasaki, M. Catalytic asymmetric synthesis of key intermediate for scytophycin C. Tetrahedron Lett. 2016, 57, 446-448. [CrossRef]

39. Moore, R.E. Constituents of blue-green algae. In Marine Natural Products; Scheuer, P.J., Ed.; Academic Press: New York, NY, USA, 1981; Volume 4, pp. 1-52.

40. Solomon, A.E.; Stoughton, R.B. Dermatitis from purified sea algae toxin (debromoaplysiatoxin). Arch. Dermatol. 1978, 114, 1333-1335. [CrossRef] [PubMed]

41. Mynderse, J.S.; Moore, R.E. Toxins from Blue-Green algae: Structures ofoscillatoxin A and three related bromine-containing toxins. J. Org. Chem. 1978, 43, 2301-2303. [CrossRef]

42. Kunifuda, K.; Iwasaki, A.; Nagamoto, M.; Suenaga, K. Total synthesis and absolute configuration of koshikalide. Tetrahedron Lett. 2016, 57, 3121-3123. [CrossRef]

43. Yadav, J.S.; Suresh, B.; Srihari, P. Stereoselective total synthesis of the marine macrolide sanctolide A. Eur. J. Org. Chem. 2015, 5856-5863. [CrossRef]

44. Frayman, K.; Robinson, P. Macrolide therapy in cystic fibrosis: New developments in clinical use. Clin. Investig. 2013, 3, 1179-1186. [CrossRef]

45. Shishido, T.K.; Humisto, A.; Jokela, J.; Liu, L.W.; Wahlsten, M.; Tamrakar, A.; Fewer, D.P.; Permi, P.; Andreote, A.P.D.; Fiore, M.F.; Sivonen, K. Antifungal compounds from cyanobacteria. Mar. Drugs 2015, 13, 2124-2140. [CrossRef] [PubMed]

46. Salvador-Reyes, L.A.; Sneed, J.; Paul, V.J.; Luesch, H. Amantelides A and B, polyhydroxylated macrolides with differential broad-spectrum cytotoxicity from a guamanian marine cyanobacterium. J. Nat. Prod. 2015, 78, 1957-1962. [CrossRef] [PubMed]

47. Wood, R. Acute animal and human poisonings from cyanotoxin exposure-A review of the literature. Environ. Int. 2016, 9, 276-282. [CrossRef] [PubMed]

48. Stierle, D.B.; Stierle, A.A.; Bugni, T.; Loewen, G. Gloeolactone, a new epoxy lactone from a blue-green alga. J. Nat. Prod. 1998, 61, 251-252. [CrossRef] [PubMed]

49. Williamson, R.T.; Boulanger, A.; Vulpanovici, A.; Roberts, M.A.; Gerwick, W.H. Structure and absolute stereochemistry of phormidolide, a new toxic metabolite from the marine cyanobacterium phormidium sp. J. Org. Chem. 2002, 67, 7927-7936. [CrossRef] [PubMed] 
50. Pereira, A.R.; McCue, C.F.; Gerwick, W.H. Cyanolide A, a glycosidic macrolide with potent molluscicidal activity from the Papua New Guinea cyanobacterium Lyngbya bouillonii. J. Nat. Prod. 2010, 73, 217-220. [CrossRef] [PubMed]

51. Bates, R.W.; Lek, T.G. A synthesis of cyanolide A by intramolecular oxa-michael addition. Synthesis 2014, 46, 1731-1738. [CrossRef]

52. Yonezawa, T.; Mase, N.; Sasaki, H.; Teruya, T.; Hasegawa, S.; Cha, B.Y.; Yagasaki, K.; Suenaga, K.; Nagai, K.; Woo, J.T. Biselyngbyaside, isolated from marine cyanobacteria, inhibits osteoclastogenesis and induces apoptosis in mature osteoclasts. J. Cell. Biochem. 2012, 113, 440-448. [CrossRef] [PubMed]

53. Gutiérrez, M.; Tidgewell, K.; Capson, T.L.; Engene, N.; Almanza, A.; Schemies, J.; Jung, M.; Gerwick, W.H. Malyngolide Dimer, a bioactive symmetric cyclodepside from the panamanian marine cyanobacterium Lyngbya majuscula. J. Nat. Prod. 2010, 73, 709-711. [CrossRef] [PubMed]

54. Gutierrez, M.; Andrianasolo, E.H.; Shin, W.K.; Goeger, D.E.; Yokochi, A.; Schemies, J.; Jung, M.; France, D.; Cornell-Kennon, S.; Lee, E. Structural and synthetic investigations of tanikolide dimer, a SIRT2 selective inhibitor, and tanikolideseco-acid from the Madagascar marine cyanobacterium Lyngbya majuscula. J. Org. Chem. 2009, 74, 5267-5275. [CrossRef] [PubMed]

55. Pereira, A.R.; Cao, Z.Y.; Engene, N.; Soria-Mercado, I.E.; Murray, T.F.; Gerwick, W.H. Palmyrolide A, an Unusually Stabilized Neuroactive Macrolide from Palmyra Atoll Cyanobacteria. Org. Lett. 2010, 12, 4490-4493. [CrossRef] [PubMed]

56. Sudhakar, G.; Reddy, K.J.; Nanubolu, J.B. Total synthesis of palmyrolide A and its 5,7-epi isomers. Org. Lett. 2010, 12, 4490-4493. [CrossRef]

57. Klein, D.; Braekman, J.C.; Daloze, D. Laingolide, a novel 15-membered macrolide from Lyngbya bouillonii (cyanophyceae). Tetrahedron Lett. 1996, 37, 7519-7520. [CrossRef]

58. Klein, D.; Braekman, J.C.; Daloze, D.; Hoffmann, L.; Castillo, G.; Demoulin, V. Madangolide and laingolide A, two novel macrolides from Lyngbya bouillonii (Cyanobacteria). J. Nat. Prod. 1999, 62, 934-936. [CrossRef] [PubMed]

(C) 2017 by the authors. Licensee MDPI, Basel, Switzerland. This article is an open access article distributed under the terms and conditions of the Creative Commons Attribution (CC BY) license (http:/ / creativecommons.org/licenses/by/4.0/). 